\title{
TITLE: 3D predictions of the local effective stress intensity factor as the fatigue crack propagation driving force
}

\author{
W. Taleb*, C. Gardin, C. Sarrazin-Baudoux \\ $\underline{\text { Wissam.taleb@ensma.fr, catherine.gardin@ensma.fr, christine.baudoux@ensma.fr }}$ \\ INSTITUT P', ISAE-ENSMA (Téléport $2 ; 1$, avenue Clément Ader, BP 40109, 86961 FUTUROSCOPE \\ CHASSENEUIL Cedex), FRANCE
}

Keywords - Fatigue crack propagation, crack front shape, plasticity induced crack closure

\section{Highlights}

- Predict three dimensional crack front shape under fatigue loading

- Demonstrate the efficiency of stress fields' method to calculate stress intensity factor

- Demonstrate the influence of plasticity induced crack closure on the crack front shape

- Establish the limitations of the use of stress fields' method beyond small scale yielding

\section{Abstract}

The objective of this study is to develop a numerical tool using the commercial software, Abaqus and Python, to predict the fatigue crack front shape while taking into account the influence of plasticity induced crack closure on crack propagation in three Dimensional (3D) structures. In this aim, a 3D model of a compact tension specimen made out of stainless steel 304L, and subjected to a constant loading scheme, is proposed. The crack propagation is considered to be driven by the stress fields developed in the vicinity of the crack tip and thus by the stress intensity factor K. Two parallel simulations are used: an elastic simulation intends to calculate the local maximum stress intensity factor while the other, an elasto-plastic one, aims at obtaining the plastic wake and the resulting crack closure load. The results of both simulations are combined in order to constitute the effective stress intensity factor range, which is in turn used, along with Paris law, to calculate the crack propagation along the thickness. The local crack advancements obtained allow to construct 
the new crack front. Finally, a node release technique is used with geometry remeshing to issue new iterations with new boundary conditions that respond to the changes in the crack front. The procedure is repeated until the stabilization of the effective stress intensity factor values all along the specimen thickness is reached. The results obtained are compared with previously issued experimental results, showing very good results in small scale yielding and beyond that a large dependency on the plastic zone size developed in the neighborhood of the crack front.

\section{Introduction}

As the initiation of cracks has shown to be inevitable in moderate and highly solicited domains, scientists have to consider the presence of cracks while respecting safety recommendations. Therefore, it is always necessary to follow the development of these cracks and thus study their initiation, propagation and failure. With respect to propagation, the most important task is to identify the crack driving force and thus to predict the body's failure.

Irwin [1], based on a previous work of Westergaard [2], was the first to define the notion of the stress intensity factor $\mathrm{K}$ to lead and predict propagation. This parameter is related to the stress and strain fields developed in the vicinity of the crack tip in an elastic medium. Newman and Raju [3] used the stress field method, to calculate $\mathrm{K}$ for a wide range of semi-elliptical surface cracks in plates of finite thickness as well as in three-dimensional bodies. De Morais [4] also analyzed different isotropic and orthotropic specimens under different modes of fracture using this method, and obtained very good results with a calculation error of K that didn't exceed $1 \%$. Likewise, Shih and Chen [5] used it to analyze the development of fatigue crack in a specimen subjected to tension, bending and a combination of these two loads. Aman et al [6] showed that it can be used to evaluate the stress intensity factor for interacting three dimensional cracks of undefined shape. In another 
context, Davood et al [7] used the stress fields' method under mixed mode fracture mechanics to predict the angle of the propagation of the crack front depending on the shear and tangential stresses; the numerical results showed to be consistent with the experimental results.

Other authors preferred using the displacement fields' method. This method was used by Lu [8] who calculated $\mathrm{K}$ for semi-elliptical surface cracks in a welded zone with complex stress fields. In addition, it has been used by a large number of authors such as [9]-[13]. In the same context, some authors [14], [15] used some energetic methods following the Griffith theory [16], [17] that consider the energy release rate as the driving force.

The major drawback of using the displacement fields' method and the energetic one is that they show great dependence on the stress state along the thickness in 3D cases. Therefore, it appears that the stress fields' method constitutes a good solution where no stress state assumption is needed.

In the 70s, Elber [18] noticed that, for some loading schemes, a specific phenomenon is taking place ahead of the crack tip. He showed that the development of the plastic wake in the crack tip region creates compressive stresses which induce, in turn, a premature crack closure, denoted Plasticity Induced Crack Closure (PICC). This has led, under cyclic loading, to the introduction of a new notion namely the effective stress intensity factor range $\Delta \mathrm{K}_{\mathrm{eff}}$, based on the stress intensity factor derived by Irwin and also taking into account the closure phenomenon: It is equal to the difference between the values of the maximum and the opening stress intensity factors.

The phenomenon of closure, like in most numerical simulations, was firstly studied in bi dimensional models by Newman [19], [20] who differentiated in his calculations the state of plane stresses and that of plane strains. Crack closure is shown to be much more important in plane stresses [21]-[23] than in plane strains relying on the fact that the opening load is greater in the 
plane stress state. Fleck [24] considers it even absent under plane strain state. On the other hand, McClung [25] considers that the difference between crack closure in both states is small.

Some authors [26]-[28] proposed a more specific study on the influence of the state of stresses on the volume considered. Dill and Saff [29] were the first to calculate the opening and closure loads based on observations of the stress state in the crack plane during cyclic loading. Sehitoglu and Sun [30], [31] considered a state of plane strains for their propagation problems. They also introduced a parameter of tensile load at the crack tip which characterizes the level of stress at the crack tip. In addition, Wu and Ellyin [32] proposed a similar concept which relies on the evolution of the state of the stress fields to calculate the opening and closure loads. Moreover, Alizadeh [33] proposed a method to calculate $\Delta \mathrm{K}_{\text {eff }}$ directly from the stress fields in front of the crack front tip. The equation used is similar to that used previously with $\Delta \mathrm{K}$, but it was replaced by $\Delta \mathrm{K}_{\mathrm{eff}}$ and some additional adjustment values.

The first 3D study, including the influence of crack closure, was issued by Chermahini [34]. However, he used a simple elasto plastic material behavior of Aluminum (elastic perfectly plastic) as well as a small number of cycles between node releases. In the same context, and in order to study the final crack front shape, Hou [11], [12] proposed a 3D model for the propagation of a semi elliptical crack in an elastic perfectly plastic material involving two parallel simulations. The first elastic simulation allowed to calculate the local maximum stress intensity factor, and the second elasto plastic one aimed at extracting the opening local stress intensity factor taking into account crack closure. The introduction of crack closure was recently studied by Camas et al [35] who presented the influence of the crack growth scheme on the three dimensional evolution of the plasticity induced crack closure in terms of the number of loading cycles and the maximum allowed penetration while in contact. 
In this manner, Vor [36] simulated the propagation of a rectilinear crack front in a CT-50 geometry, in an austenitic stainless steel 304L using an elastoplastic constitutive law developed by Chaboche [37] to take into account the crack closure. He used the node release technique to simulate the propagation with a maximum crack advancement of $0.05 \mathrm{~mm} .15$ cycles were simulated between successive releases. Thus he validated numerically the presence of the closure at the free surface rather than at the center. The main limitation in his approach was the shape of the crack fronts remaining rectilinear throughout propagation, while the experimental results showed a curvature, more or less pronounced, according to the loading conditions. Despite the work of setting up a very interesting 3D model, it was clear that the method must be refined and that the shape of the crack front should be updated to take into account the curvature.

Improvements were made by Fiordalisi [38], with the implementation of an adaptive remeshing technique allowing updating the meshing scheme at each crack advance based on the assumption that the effective stress intensity factor range is the driving force. The initial crack front is rectilinear. The local effective stress intensity factor range was obtained through both elastic and elasto plastic calculations. The K values were calculated using the method developed by Shih and Asaro [39], an energy dependent method. Fiordalisi [38] investigated, under different loading conditions, several different predefined crack shapes and mainly elliptical shapes often used in literature for crack fronts. The numerical results were generally consistent with experiments, even if the predicted curvature was systematically lower than the experimental one. This may be explained by the underestimation of the predicted crack closure at the edge. In addition, Gardin et Al. [38] observed that the K values calculated by the Shih and Asaro method were very close to plane strain values almost all along the specimen thickness, even near the free surface where a 
plane stress state prevails ignoring the evolution of this state along the thickness in three dimensional studies.

The objectives of the present paper are to develop a three dimensional numerical model taking into account, more precisely, the influence of the plasticity induced crack closure all over the thickness. To this aim, the stress fields' method is used for the calculation of the local maximum stress intensity factor in order to avoid any hypothesis on the stress state along the thickness. No predefined crack shape will be imposed throughout propagation. The final numerical crack front results will be compared with previously issued experimental results [36], [38], [40] to assess the robustness of the method.

\begin{tabular}{|c|c|c|c|}
\hline \multicolumn{4}{|c|}{ Nomenclature: } \\
\hline CT : & Compact tension & $\mathbf{P}_{\max }:$ & $\begin{array}{l}\text { Maximum applied load (superscript } \ell \text { : } \\
\text { local) }\end{array}$ \\
\hline$\Delta \mathbf{K}:$ & Stress intensity factor range & & Crack closure rate (superscript $\ell$ : local) \\
\hline$\Delta K_{e f f}:$ & $\begin{array}{l}\text { Local effective stress intensity factor } \\
\text { range (superscript } \ell \text { : local; (Subscript i: } \\
\text { at node i) }\end{array}$ & $\sigma_{\mathrm{yy}}$ & $\begin{array}{l}\text { Stresses perpendicular to the crack } \\
\text { plane }\end{array}$ \\
\hline$K^{\ell}:$ & $\begin{array}{l}\text { Local maximum stress intensity factor } \\
\text { range(superscript } \ell \text { : local) }\end{array}$ & $\mathbf{U}_{\mathbf{y}}$ & $\begin{array}{l}\text { Displacement perpendicular to the } \\
\text { crack plane (superscript } \ell \text { : local) }\end{array}$ \\
\hline$K_{o p}:$ & $\begin{array}{l}\text { Local opening stress intensity factor } \\
\text { range (superscript } \ell \text { : local) }\end{array}$ & PEEQ: & Magnitude of Accumulated plastic strain \\
\hline PICC: & Plasticity induced crack closure & $\mathbf{a}$ & Crack length \\
\hline $\mathbf{R}:$ & Load ratio & $\mathbf{W}$ & Ligament length \\
\hline $\mathbf{P}_{\text {op }} \quad:$ & $\begin{array}{l}\text { Opening applied load (superscript } \ell \text { : } \\
\text { local) }\end{array}$ & $\Delta \mathbf{a}_{\mathrm{f}-\mathrm{c}}:$ & $\begin{array}{l}\text { Difference in crack length between center } \\
\text { and free surface }\end{array}$ \\
\hline
\end{tabular}

\section{Numerical model}

The geometry of the test specimens conforms to the geometry of a standardized compact tension test specimen CT-50 with a thickness of $10 \mathrm{~mm}$ as shown in Figure 1. For reasons of symmetry, 
only one quarter of the specimen is modeled in the simulations. For the same reason, $y=0$ and $z=$ 0 , symmetry planes are blocked in translation in the $\mathrm{y}$ and $\mathrm{z}$ directions respectively.
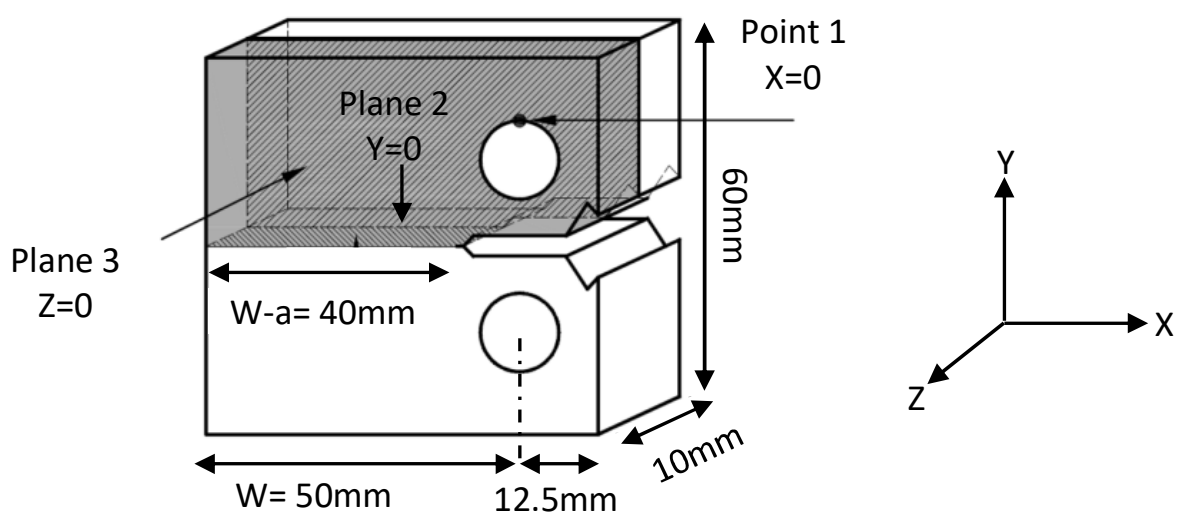

Figure 1: Geometry of the CT-50 specimen

The material studied is a 304L austenitic stainless steel, according to the AISI nomenclature. Vor [36] proposed an appropriate constitutive law of this material after having collected parameters from various monotonic and cyclic tensile tests. He found that the constitutive law of the material corresponds to that proposed by Chaboche [37], which represents both hardening behavior, isotropic behavior expressed with an exponential law and a kinematic law. These behaviors reflect the Bauschinger [41] and ratchetting [42] effects of the material.

The specimen is subjected to cyclic loading in pure mode I with a constant $\Delta \mathrm{K}$ in order to ignore the influence of over and under loads. To keep this value constant, the load F applied on the specimen is reduced progressively during propagation and calculated by the relation below:

$$
F=\frac{K_{\mathrm{I}} \cdot B \cdot \sqrt{W}}{Y}
$$

Where: 
$\mathrm{F}$ is the load applied by a pin on the holes of the specimen, $\mathrm{K}_{\mathrm{I}}$ is the stress intensity factor in mode $\mathrm{I}, \mathrm{B}$ is the thickness of the specimen, $\mathrm{W}$ is the length of the ligament and $\mathrm{Y}$ is a form factor calculated for a CT specimen as follows:

$$
Y=\frac{(2+A)\left(0.886+4.64 A-13.32 A^{2}+14.72 A^{3}-5.62 A^{4}\right)}{(1-A)^{3 / 2}}
$$

With $\mathrm{A}=\mathrm{a} / \mathrm{W}>0.2$, where $\mathrm{a}$ is the crack length measured from the center of the specimen hole to the bottom of the notch. This length a is measured at the surface of the test specimen as used during the experimental test conditions.

The studied loading conditions in this work are the following: $\Delta \mathrm{K}=4$ and $12 \mathrm{MPa} \sqrt{\mathrm{m}}$ at $\mathrm{R}=0.7$ and $\Delta \mathrm{K}=12,15$ and $18 \mathrm{MPa} \sqrt{ } \mathrm{m}$ at $\mathrm{R}=0.1$.

The contact between the lips of the crack is achieved through a rigid surface, placed on the propagation front in order to prevent the interpenetration of the nodes on the lips. The crack lip is considered the slave surface while the rigid surface is considered the master one. The Node-toSurface scheme is preferred here because it requires less computational time; several tests showed there exists almost no difference with the Surface-to-Surface' scheme results. The AugmentedLagrange contact algorithm is used in this case.

The geometry of the specimen is divided into two main parts: the first constitutes a small region in the vicinity of the crack front with a very fine mesh in order to capture large stress gradients, while the second, with a coarser mesh, constitutes the region far from the crack tip which is thus insensitive to crack fields. The two parts are then connected by a * Tie interaction integrated in ABAQUS as shown in Figure 2. 


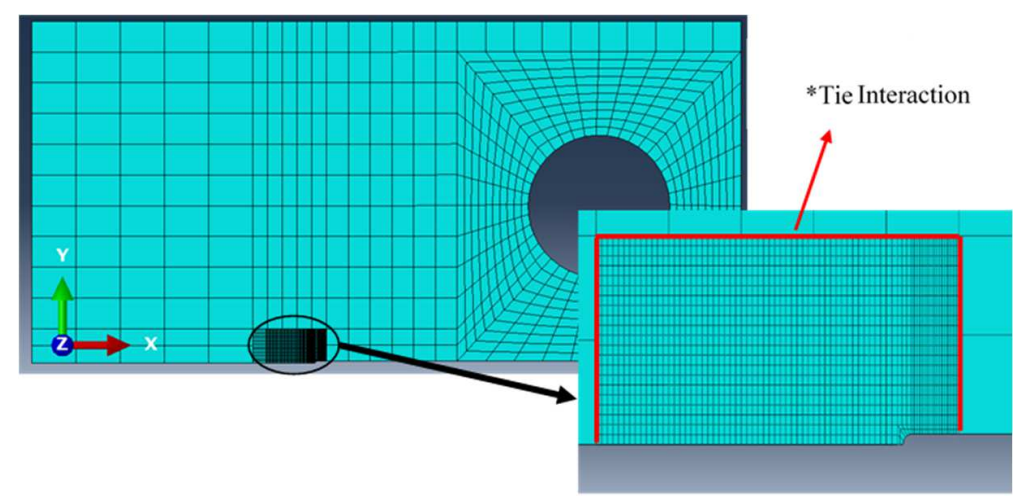

Figure 2: Fine and coarse meshes on the two parts of the geometry

Eight-noded linear hexahedral elements with reduced integration (C3D8R) are used in the refined zone close to the crack front in order to reduce the computation time. Particular attention is given throughout the propagation to ensure that no Hourglass effect is generated due to the use of these elements. After several tests, it appears that 20 elements are sufficient to obtain the best ratio, quality/time, along the thickness with refinement towards the free surface. In the plane of propagation, the maximum element size is chosen to be equal to $0.1 \mathrm{~mm}$ which is much smaller than the plastic zone developed around the crack tip as recommended by Dugdale [43].

It is necessary here to study the size of the monotonic plastic zone in order to check the validity of linear elastic fracture mechanics. The ASTM E647 standards [44] have defined these limits: they were based on the analytical bi dimensional calculations provided by Irwin [45], which appear to be invalid in $3 \mathrm{D}$ problems due to several aspects related to the material behavior, the loading conditions and the stress state along the thickness. The results given in Table 1 show that the maximum size of the calculated plastic zone is much smaller than that with Irwin's plane stress assumption (at free surface usually) with an error of around $40 \%$. Moreover, its minimum size is 
larger than that under Irwin's plane strain assumption (at center usually) with an error that ranges from 40 to $75 \%$.

Table 1 : Comparison between the optimum initial plastic zone sizes in propagation direction along the thickness using a combined hardening constitutive law with those calculated by Irwin in $2 D$ conditions for various loading conditions

\begin{tabular}{|c|c|c|c|c|}
\cline { 2 - 5 } \multicolumn{1}{c|}{} & $\begin{array}{c}\text { Irwin plane } \\
\text { stress (2D) }(\mathrm{mm})\end{array}$ & $\begin{array}{c}\text { Maximum size of } \\
\text { plastic zone (3D) } \\
(\mathrm{mm})\end{array}$ & $\begin{array}{c}\text { Minimum size of } \\
\text { plastic zone (3D) } \\
(\mathrm{mm})\end{array}$ & $\begin{array}{c}\text { Irwin plane } \\
\text { strain (2D) (mm) }\end{array}$ \\
\hline$\Delta \mathrm{K}=12 \mathrm{MPa} \sqrt{\mathrm{m}}, \mathrm{R}=0.1$ & 4.1 & 2.3 & 1.1 & 0.7 \\
\hline$\Delta \mathrm{K}=15 \mathrm{MPa} \sqrt{\mathrm{m}}, \mathrm{R}=0.1$ & 6.5 & 3.9 & 2.2 & 1.1 \\
\hline$\Delta \mathrm{K}=18 \mathrm{MPa} \sqrt{\mathrm{m}}, \mathrm{R}=0.1$ & 9.3 & 5.1 & 4 & 1.6 \\
\hline$\Delta \mathrm{K}=4 \mathrm{MPa} \sqrt{\mathrm{m}}, \mathrm{R}=0.7$ & 4.1 & 2.3 & 1.1 & 0.7 \\
\hline$\Delta \mathrm{K}=12 \mathrm{MPa} \sqrt{\mathrm{m}}, \mathrm{R}=0.7$ & 37.2 & 24.9 & 24.9 & 6.2 \\
\hline
\end{tabular}

For $\Delta \mathrm{K}=12 \mathrm{MPa} \sqrt{\mathrm{m}}, \mathrm{R}=0.1$ the maximum plastic zone constitutes approximately $10 \%$ of the length of the crack as well as of the distance till the extremities of the specimen. This percentage increases as the load increases. For $\Delta \mathrm{K}=18 \mathrm{MPa} \sqrt{\mathrm{m}}, \mathrm{R}=0.1$, the plasticity covers a really wider volume, as can be seen in Figure 3 which constitutes more than $25 \%$ of the distance between the crack and the specimen extremities. Finally, for $\Delta \mathrm{K}=12 \mathrm{MPa} \sqrt{\mathrm{m}}, \mathrm{R}=0.7$, one can see in Figure 4 that the plasticity covers all the region after the crack front until the extremities. 


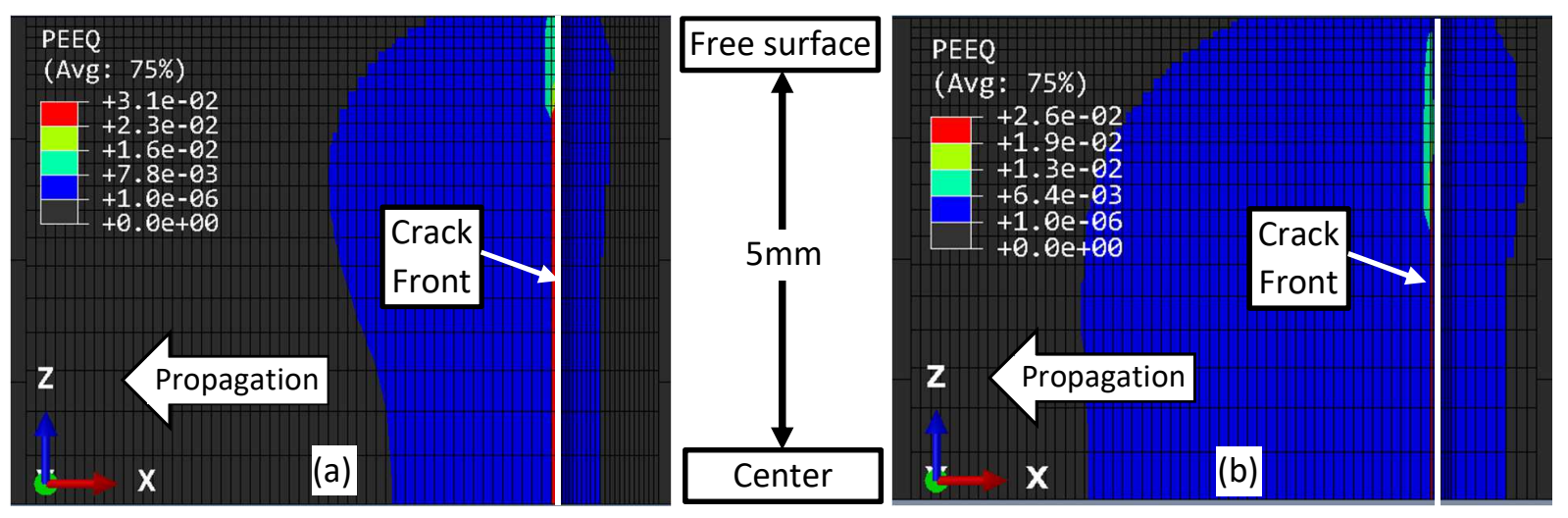

Figure 3 : Accumulated plastic strain PEEQ showing the size of the monotonic plastic zone after first loading half cycle for (a) $\Delta K$

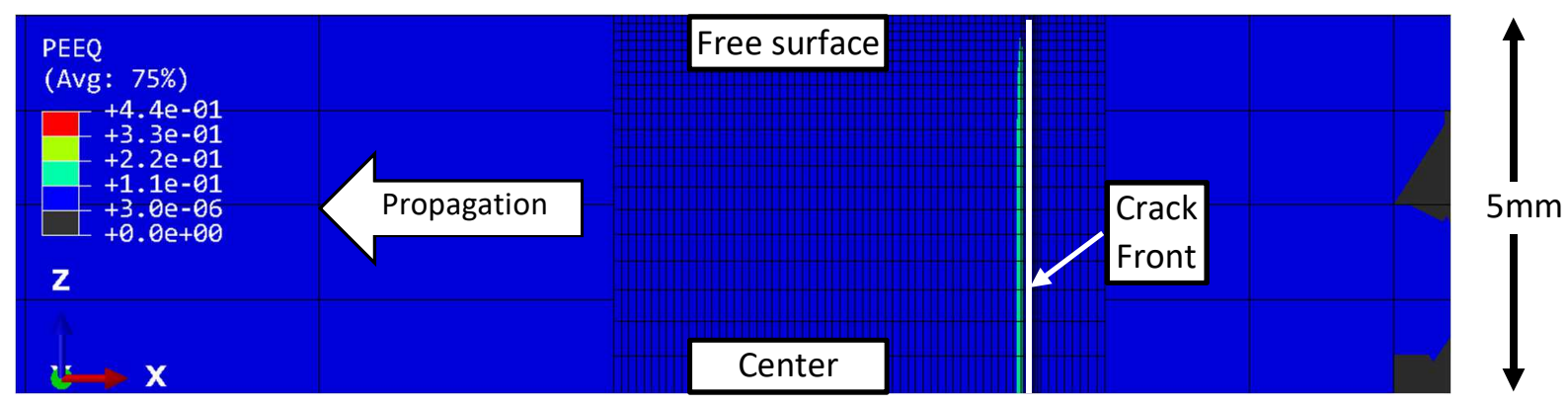

Figure 4: Accumulated plastic strain PEEQ showing the size of the monotonic plastic zone after first loading half cycle for $\triangle K=$ $12 \mathrm{MPaVm}, R=0.7$

\section{Methodology}

\subsection{Procedure}

The crack propagation, in this study, is considered to be governed by the local effective stress intensity factor range $\Delta K_{e f f}^{\ell}$. In order to determine its value, two parallel simulations are issued: the first one is an elastic simulation, for the calculation of the maximum local stress intensity factor 
$K_{\text {max }}^{\ell}$ using the stress fields' method. The second one is an elasto-plastic simulation that takes into account the effect of the crack closure by calculating the opening stress intensity factor $K_{o p}^{\ell}$. The results of these two simulations are collected at each node of the crack front along the thickness. The effective local stress intensity factor $\Delta K_{e f f}^{\ell}$ is then calculated using the following equation.

$$
\Delta K_{\text {eff }}^{\ell}=K_{\max }^{\ell}-K_{o p}^{\ell}
$$

On the basis of the modified Paris law proposed by Lin and Smith [46]-[48], the advancement $\Delta \mathrm{a}_{\mathrm{i}}$ of the crack is calculated for each node $\mathrm{i}$. The maximum advancement, $\Delta a_{\max }$, equal to $0.1 \mathrm{~mm}$ is imposed at the node where $\Delta K_{e f f, i}^{\ell}$ is the maximum, generally at the specimen center.

$$
\Delta a_{i}=\left(\frac{\Delta K_{e f f, i}^{\ell}}{\Delta K_{e f f, \max }^{\ell}}\right)^{m} \Delta a_{\max }
$$

Where $\mathrm{m}$ is the Paris law exponent and $\Delta K_{e f f, \max }^{\ell}$ is the maximum effective stress intensity factor along the crack front.

The calculated advancements then constitute the new crack front to be integrated in the geometry in Abaqus which usually uses a cubic spline fit to join consecutive nodes. This change in geometry implies an update of the existing mesh scheme in order to correspond to these changes, referred to, as remeshing. Moreover, the boundary conditions are modified shifting to the new front using the node release technique, while updating the loading conditions at the same time, in order to maintain a constant applied stress intensity factor range as the crack length increases.

This procedure is repeated at each propagation step until the mean difference stabilization criterion, $E_{\text {mean_dif }}$ implemented here, is reached. This criterion represents the summation of the differences 
between the values of $\Delta K_{e f f, i}^{\ell}$, at each node i of the crack front, and the average of these values as shown in the following equation:

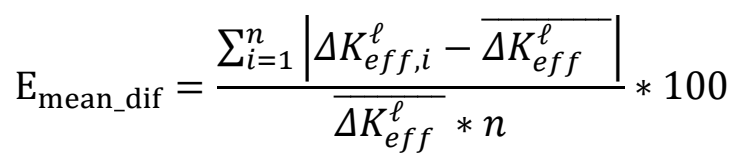

Where $\overline{\Delta K_{e f f}^{\ell}}$ is the average value of $\Delta K_{e f f, i}^{\ell}$ over the 'n' nodes of the thickness.

\subsection{Calculation of the local maximum stress intensity factor $K_{\max }^{\ell}$}

The analytical approach of Westergaard [2] and Irwin [1] is implemented in the elastic numerical model to calculate $K_{\max }^{\ell}$ using the stress fields in the vicinity of the crack tip. Considering the fact that loading in this case is uniaxial (Westergaard [2] - equivalent biaxial), only the stresses perpendicular to the crack propagation plane $\sigma_{\mathrm{yy}}$ are used to eliminate additional unknowns as the T-stress, usually considered for the stresses parallel to crack propagation plane $\sigma_{\mathrm{xx}}$. The use of the nodes located after the crack front on the propagation plane helps reduce the stress intensity factor equation to its following final form:

$$
\sigma_{y y}=\frac{K_{\max }^{\ell}}{\sqrt{2 \pi r}}
$$

Where $r$ is the distance between the nodes retained and the crack front.

The calculation procedure is implemented in a Python program linked directly to post processing in Abaqus. The concerned nodes' information are classified in three main matrices. The matrix, coordinates $\mathrm{z}$, defines the positions of the nodes of the crack front in the thickness. A second and 
third matrix respectively classify the stresses and distances from the crack front for all the nodes of the uncracked part of the crack plane for the different $\mathrm{Z}$ positions in the thickness (Figure 5a).
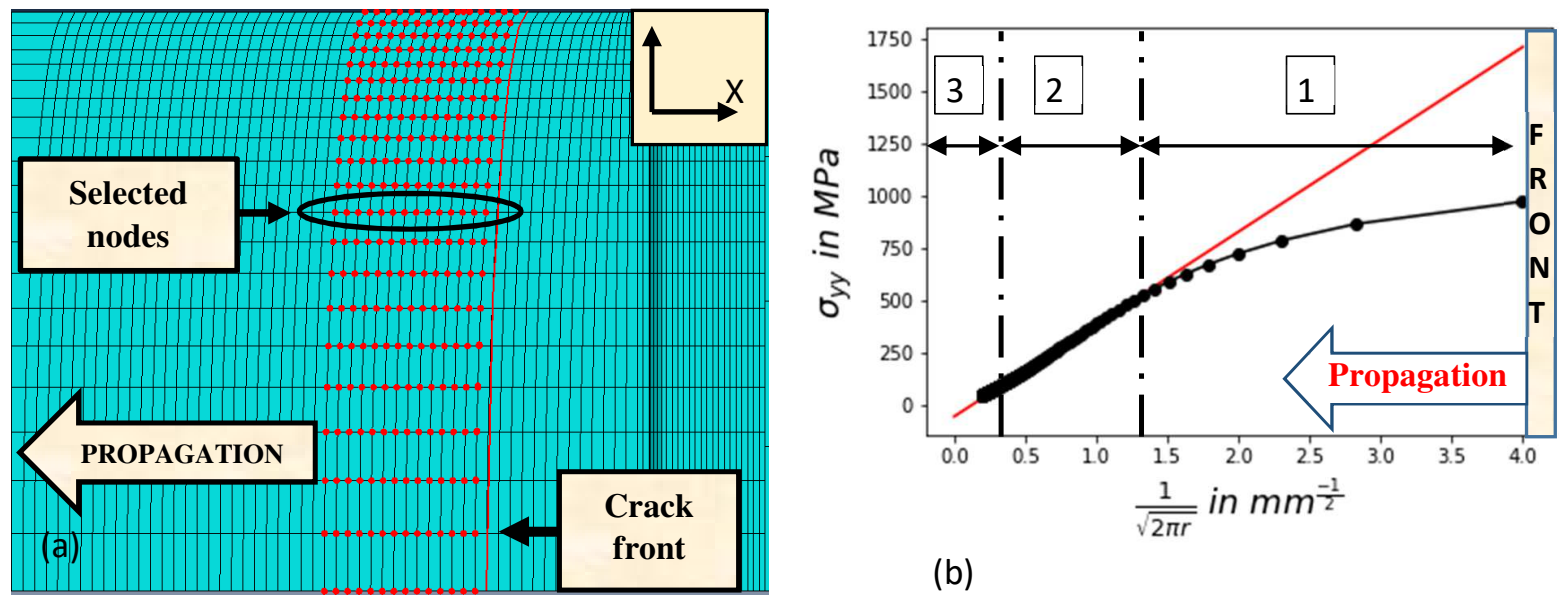

(b)

Figure 5 : (a) nodes used for the interpolation of $K_{\max }^{\ell}$ after few iterations (b) example of evolution of $\sigma_{y y}$ stresses vs $1 / \sqrt{ } 2 \pi r$ for the nodes after the crack front

The stresses are then interpolated as a function of $1 / \sqrt{2} \pi r$ as shown in Figure $5 \mathrm{~b}$. The evolution of $\sigma_{\mathrm{yy}}$ can be divided into three main zones. The first one, the closest to the crack front, is strongly disturbed associated to non-linearity due to high singularities. The second zone is a zone of linearity which allows to obtain a unique value of the slope $K_{\max }^{\ell}$. This zone is thus considered as the best position for interpolation. However, the boundaries of this area are not always easy to determine. In fact, there is no general rule or relationship that fixes this interval. The third zone is the furthest from the crack front with less non-linearity than zone 1 . The calculation of $K_{\max }^{\ell}$ in this zone would probably require introducing additional higher order terms in equation 6. 


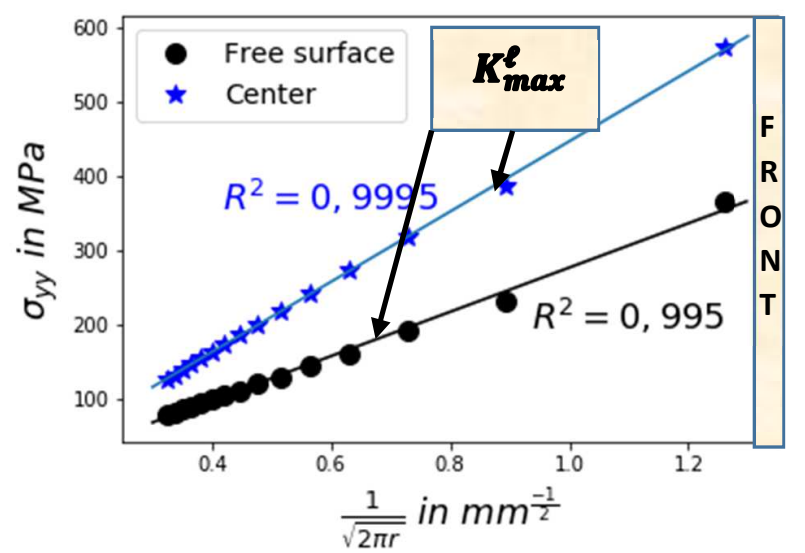

Figure 6: $K_{\max }^{\ell}$ calculated as the slope of the curve: $\sigma_{y y}$ vs $1 / \sqrt{ } 2 \pi r(\Delta K=4 M P a v m, R=0.7,1$ s iteration)

Following several studies of the interpolation curves after different iterations, for different front curvatures and positions in the thickness, the retained interval of interpolation is $[0.1-1.5 \mathrm{~mm}]$, found to be usually located in the second region. The stress values in this interval are linearly interpolated with the value of $K_{\max }^{\ell}$ represented by the slope (Figure 6).

The linearity of the stress values as a function of $1 / \sqrt{2} \pi r$ is in agreement with the analytical formulations for the different $\mathrm{z}$ positions in the thickness. Near the free surface, the quality of the interpolation is poorer than further. This may be referred to vertex singularity which was presented by authors like Hutar [49] to have a unique behavior in around $10 \%$ of the region close to the free surface.

\subsection{Calculation of the local opening stress intensity factor $K_{o p}^{\ell}$}

The local displacement perpendicular to the crack plane, $U_{y}^{\ell}$, is considered here to correspond to the opening or the closing of the crack. When $U_{y}^{\ell}$ becomes positive during loading, it means that the crack locally opens and thus the local opening load $P_{o p}^{\ell}$ can be calculated. When $\mathrm{U}_{\mathrm{y}}$ becomes equal to zero during unloading, the local closure load $P_{c l}^{\ell}$ can be calculated. There is a small difference between these two values which can be related to the plasticity that occurs during the 
loading cycle. In this study, the local opening load will be used to detect the opening with a retained minimum value $U_{y}=9 * 10^{-9} \mathrm{~mm}$. Since the crack closure develops before the crack front, these displacements and the opening local $P_{o p}^{\ell}$ loads are collected on the crack front that positioned just before the present one at a distance lower than $0.1 \mathrm{~mm}$.

$K_{o p}^{\ell}$ is then calculated using the following relationship between the loads and the stress intensity factors:

$$
K_{o p}^{\ell}=K_{\max }^{\ell} \frac{P_{o p}^{\ell}}{P_{\max }^{\ell}}
$$

\section{Results}

\subsection{Absence of crack closure}

For tests carried out with a high load ratio $\mathrm{R}$, crack closure is rarely present. The tested corresponding loading conditions are $\Delta \mathrm{K}=4$ and $12 \mathrm{MPa} \vee \mathrm{m}$ with $\mathrm{R}=0.7$ : the loading ratio is high enough to ensure the absence of crack closure. The driving force of propagation, in such cases, corresponds to the local amplitude of the stress intensity factor $\Delta \mathrm{K}$, assumed to have a unique value all over the thickness after stabilization. In fact, in the absence of crack closure, $\Delta \mathrm{K}$ is proportional to the local maximum stress intensity factor $K_{\max }^{\ell}$ with $\Delta K=K_{\max }^{\ell}(1-R)$. For that reason, in what follows, only the evolution of $K_{\max }^{\ell}$ will be presented. For $\Delta \mathrm{K}=12 \mathrm{MPa} \vee \mathrm{m}$, to achieve stabilization (equation 5), 28 iterations were necessary. The stabilization error shows to be decreasing rapidly throughout propagation (Figure 7a) with a final value close to zero. 

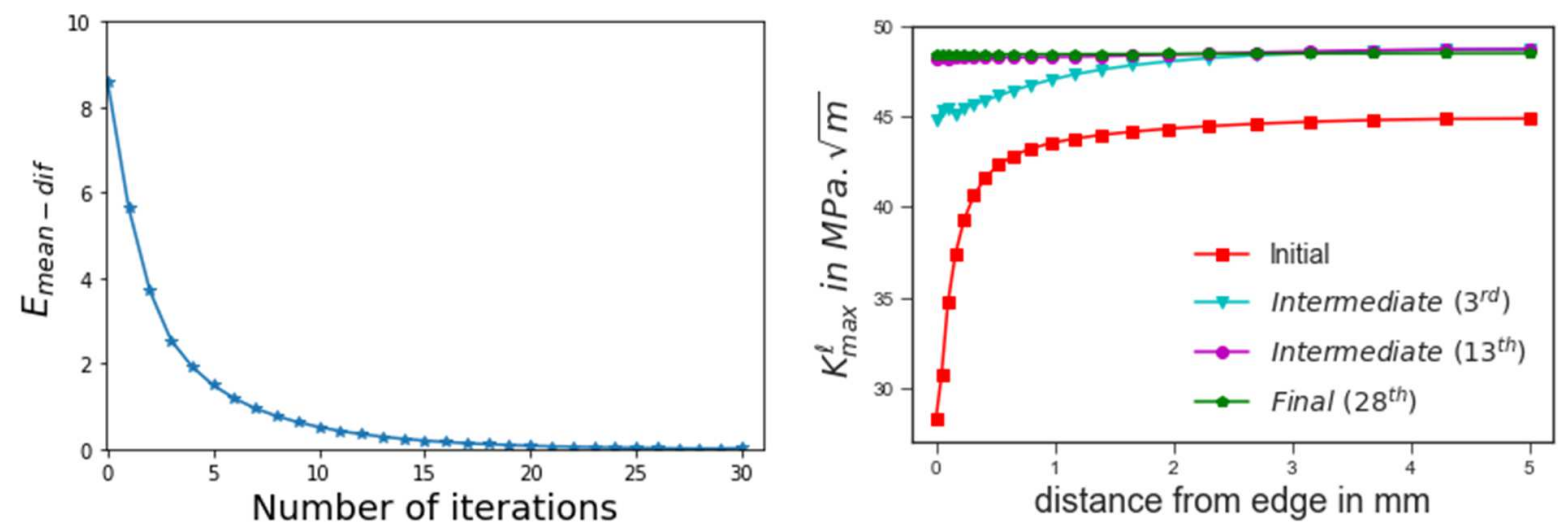

Figure 7: $\Delta K=12 \mathrm{MPaVm} ; R=0.7$ (a) Stabilization error $E_{\text {mean_dif }} v$ s number of iterations $\quad$ (b) $K_{\text {max }}^{\ell}$ in the half thickness at

different stages of propagation

$K_{\max }^{\ell}$ is plotted as a function of the distance from the edge in Figure $7 \mathrm{~b}$ for several stages of propagation: initial, intermediate and final. $K_{\max }^{\ell}$ evolution is found to be completely identical for the two loading conditions 4 and $12 \mathrm{MPa} \sqrt{\mathrm{m}}$ with $\mathrm{R}=0.7$ which is consistent with the elastic behavior. The initial curve corresponds to the initial rectilinear crack front; the value of $K_{\max }^{\ell}$ is much lower at the free surface than at the center. This difference tends to decrease as the crack propagates before stabilizing at the final iteration where the values of $K_{\max }^{\ell}$ converge to a unique value over the entire thickness. The values at the center are almost constant throughout the propagation. The final stabilized values of $K_{\max }^{\ell}$ are close to $16 \mathrm{MPa} \sqrt{\mathrm{m}}$ for $\Delta \mathrm{K}=4 \mathrm{MPa} \sqrt{\mathrm{m}}$ and 48.5 MPa $\sqrt{\mathrm{m}}$ for $\Delta \mathrm{K}=12 \mathrm{MPa} \sqrt{\mathrm{m}}$ which corresponds to approximately $20 \%$ higher values than the global imposed which are 13.33 and $40 \mathrm{MPa} \sqrt{ }$ m respectively.

The resulting shape of the 'spline' crack front is compared, in Figure 8, with that of an ellipse constructed by interpolating the crack front nodes throughout propagation. This comparison aims to check if the shape of the obtained crack front is close to the elliptical form generally proposed throughout the literature. It is clear that the first fronts are rather far from being described by an 
ellipse. However, as stabilization approaches, the elliptical shape of the front becomes more and more evident. The last crack front can be perfectly described by an ellipse.
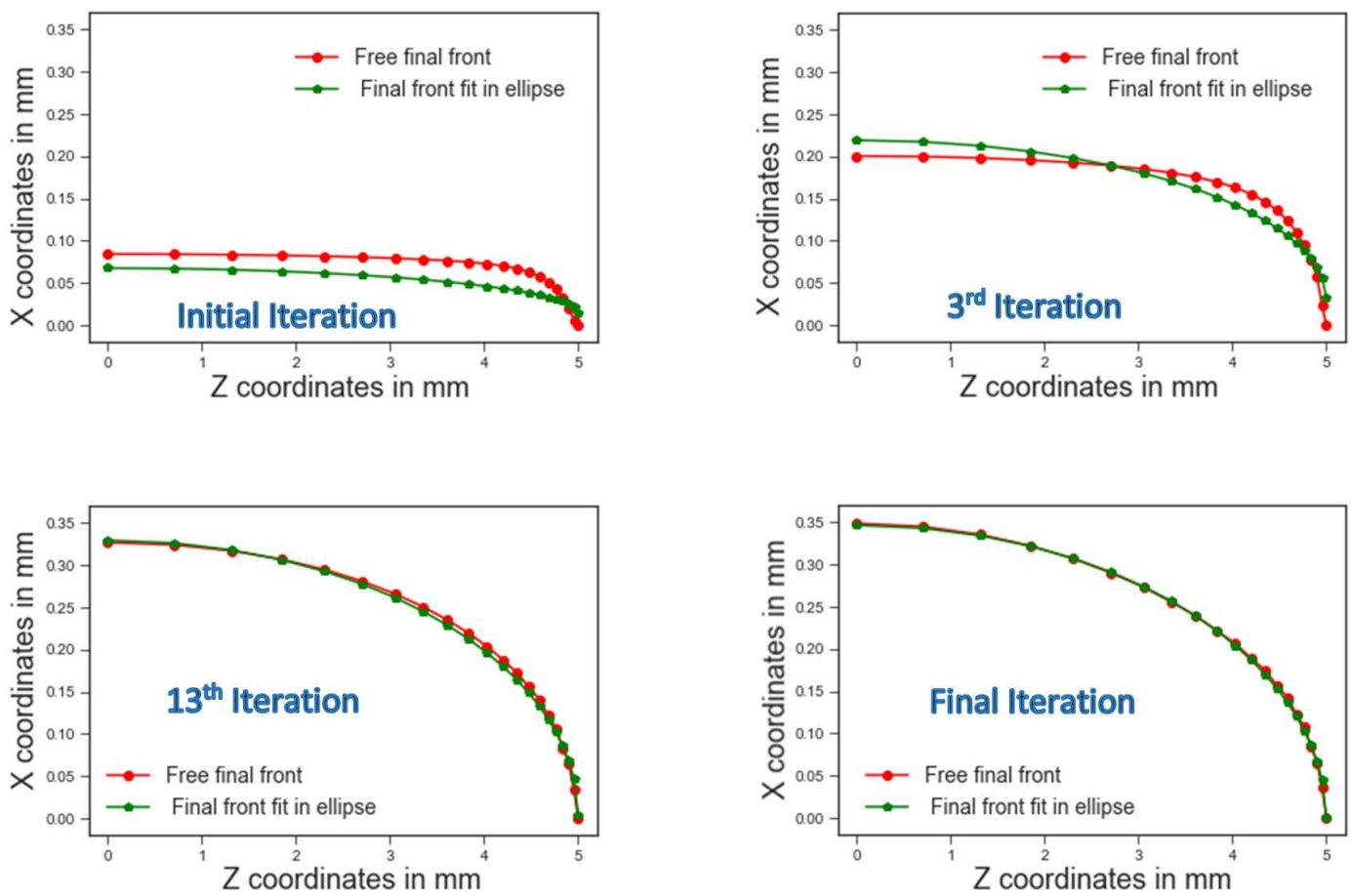

Figure 8: Comparison between the 'spline' front shapes with their elliptical interpolation for $\Delta K=4$ and $12 \mathrm{MPaVm} ; R=$

0.7

\subsection{Presence of crack closure}

In the presence of crack closure, the propagation is controlled by the amplitude of the effective local stress intensity factor $\Delta K_{e f f}^{\ell}$. The corresponding studied loading conditions are the following: $\Delta \mathrm{K}=12,15$ and $18 \mathrm{MPa} \sqrt{ } \mathrm{m}$ with $\mathrm{R}=0.1$ 


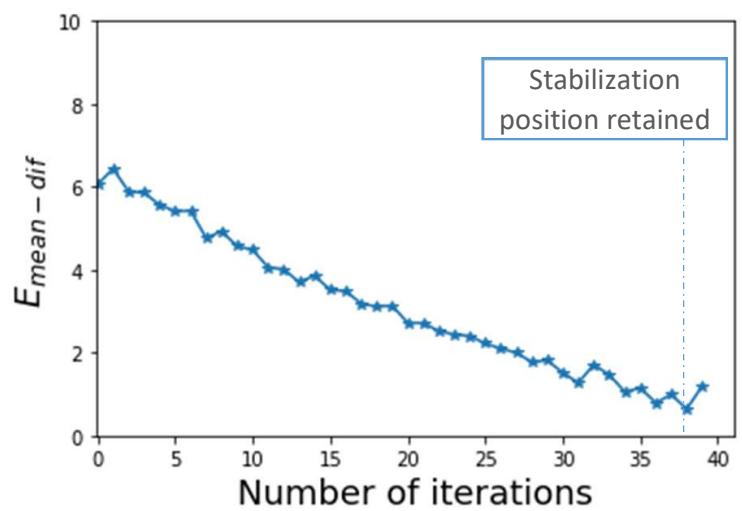

Figure 9: Evolution of the stabilization error on $\Delta K_{\text {eff }}^{\ell}$ vs number of iterations, $\Delta K=12 \mathrm{MPaVm} ; R=0.1$

The stabilization seems here to be slower with the presence of crack closure, however the error still tends towards zero as shown in Figure 9. The same behavior is observed for all the other loading conditions with the values of the stabilization errors given in Table 2.

Table 2 : Number of iterations necessary to minimize the error for different loading conditions, and corresponding error values

\begin{tabular}{|c|c|c|}
\cline { 2 - 3 } \multicolumn{1}{c|}{} & Iterations until stabilization & Minimum error \\
\hline$\Delta \mathrm{K}=12 \mathrm{MPa} \sqrt{\mathrm{m}} ; \mathrm{R}=0.1$ & 38 & $0.64 \%$ \\
\hline$\Delta \mathrm{K}=15 \mathrm{MPa} \sqrt{\mathrm{m}} ; \mathrm{R}=0.1$ & 42 & $0.73 \%$ \\
\hline$\Delta \mathrm{K}=18 \mathrm{MPa} \sqrt{\mathrm{m}} ; \mathrm{R}=0.1$ & 36 & $0.81 \%$ \\
\hline
\end{tabular}

\subsubsection{Evolution of the local maximum stress intensity factor}

Figure 10a shows the values of $K_{\max }^{\ell}$ along the thickness of the CT specimen for different stages of propagation for $\Delta \mathrm{K}=12 \mathrm{MPa} \sqrt{\mathrm{m}}$ with $\mathrm{R}=0.1$. At the beginning of propagation, there is a significant difference between the values at the free surface and the center, with much lower values in the vicinity of the free surface. This difference decreases during propagation with almost 
constant center values. At the final stage, the values at the free surface become much higher than those at the center.
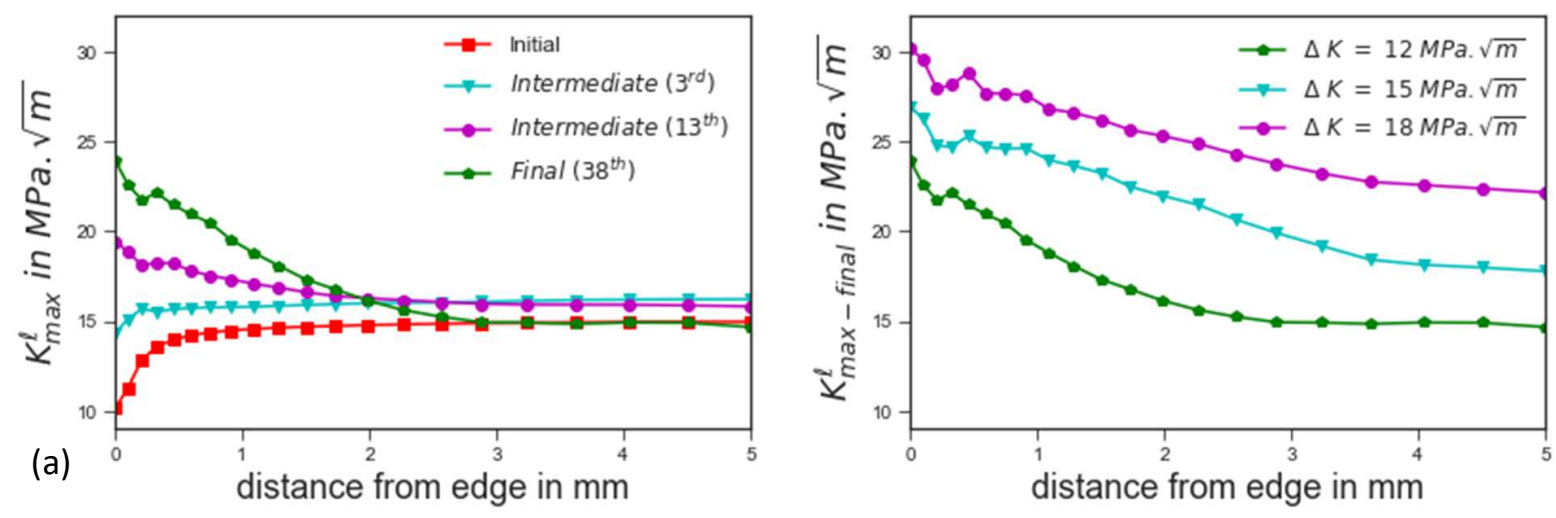

Figure 10 : Evolution of $K_{\max }^{\ell}$ in the specimen thickness (a) at different stages of propagation for $\Delta K=12 \mathrm{MPaVm} ; R=0.1$ (b)

for different loading conditions at the final step

Figure $10 \mathrm{~b}$ illustrates $K_{\max }^{\ell}$ as a function of the position in the thickness for the various levels of $\Delta \mathrm{K}$ imposed and this for the stabilized fronts. The curves are almost proportional to each other. However, a small disturbance can be remarked in the free surface region. For $\Delta \mathrm{K}=12,15$ and 18 $\mathrm{MPa} \sqrt{\mathrm{m}}$ with $\mathrm{R}=0.1$, the final values of $K_{\max }^{\ell}$ at the center are respectively $14.4,17.7$ and 22.4 $\mathrm{MPa} \sqrt{\mathrm{m}}$. Regarding the first two conditions, the difference with the global imposed values, around 14 and $16 \mathrm{MPa} \sqrt{\mathrm{m}}$, is acceptable; however, for $\Delta \mathrm{K}$ equal to $18 \mathrm{MPa} \sqrt{\mathrm{m}}$, the imposed $20 \mathrm{MPa} \sqrt{\mathrm{m}}$ value is further from that calculated locally with a $12 \%$ difference.

\subsubsection{Crack closure evolution}

The evolution of crack closure is presented here using different approaches. First, in Figure 11a, the local opening stress intensity factor $K_{o p}^{\ell}$ is presented. In Figure $11 \mathrm{~b}$ the local crack closure rate $U^{\ell}$, is plotted, defined as follows: 


$$
U^{\ell}=1-\frac{K_{\max }^{\ell}-K_{o p}^{\ell}}{K_{\max }^{\ell}-K_{\min }^{\ell}}
$$

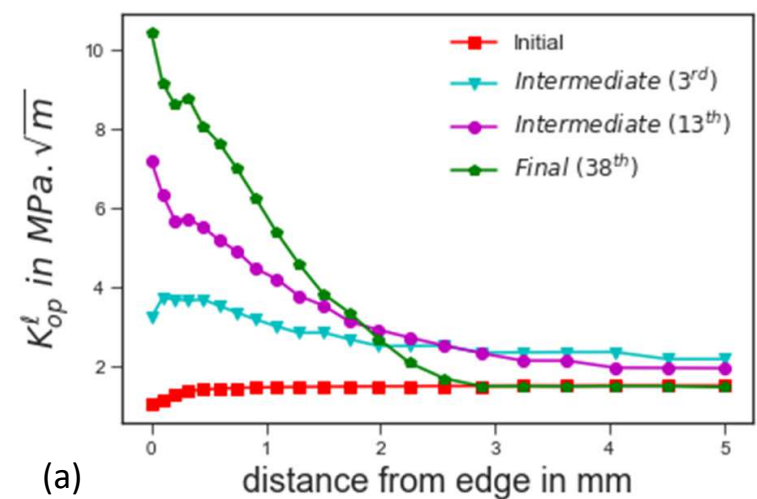

Figure 11: $\Delta K=12 \mathrm{MPaVm} ; R=0.1$ (a) local opening SIF $K_{o p}^{\ell}$

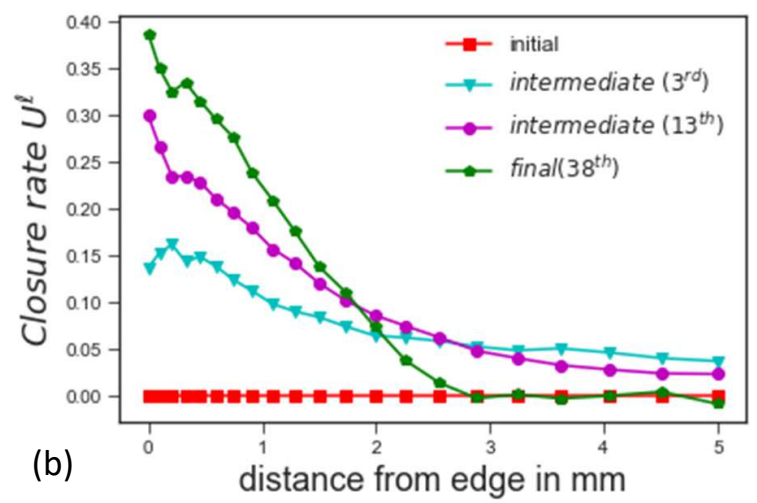

(b) local crack closure rate $U^{\ell}$

For the initial iteration, $K_{o p}^{\ell}$ is slightly smaller at the free surface than at the center with values very close to $K_{\min }^{\ell}$ (equal to $K_{\max }^{\ell} / 10$ for $\mathrm{R}=0.1$ in this case) as almost no crack closure is present. The corresponding value of $U^{\ell}$ is almost equal to zero all along the thickness. This can be shown in Figure 12a which presents the magnitude of the accumulated plastic strain PEEQ for the first iteration where it is clear that the plastic wake is not yet sufficiently developed to induce crack closure.

During propagation, $K_{o p}^{\ell}$ strongly increases at the edge with almost constant values at the center where a small amount of crack closure is observed. Meanwhile, the accumulation of the plastic wake increases with the propagation (Figure 12b). As expected, crack closure has a stronger influence near the specimen edges than at the center. At the final iteration, six nodes near the center are still opened (Figure 11b) meaning that they are not influenced by closure. 

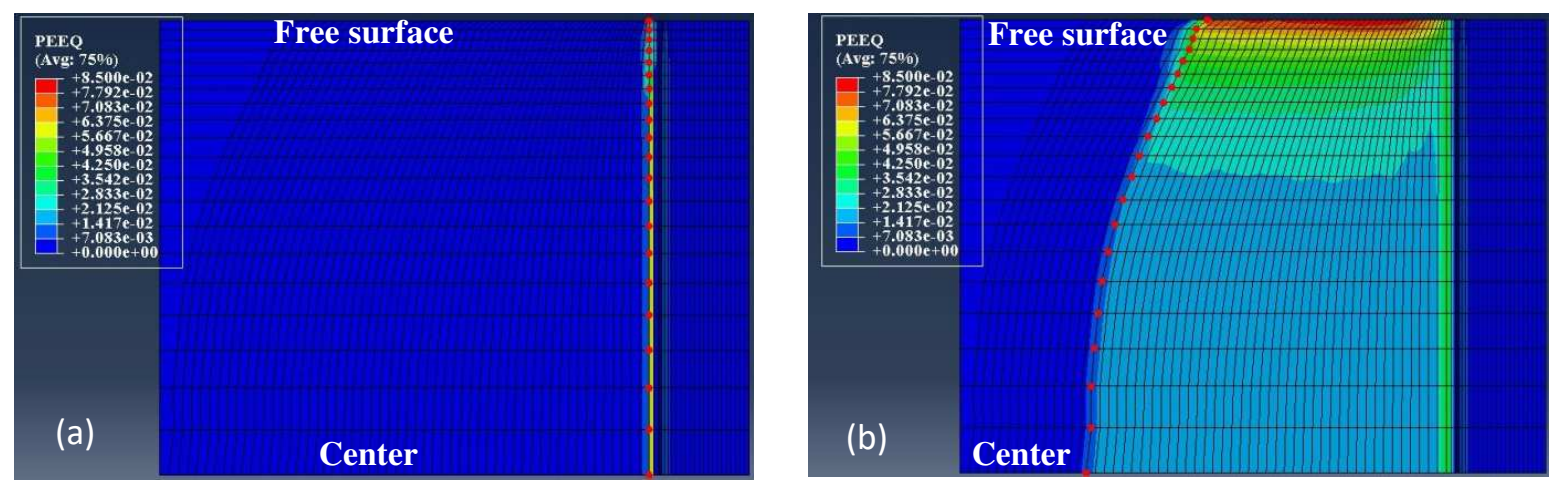

Figure 12: Accumulated cyclic plastic strain at the minimum applied load for $\Delta K=12 \mathrm{MPaVm} ; R=0.1:$ (a) initial front (b) final front

This is also confirmed by the stress and displacement fields in the vicinity of the crack front. Figure 13a illustrates the $\sigma_{y y}$ compressive stresses surrounding the crack front and perpendicular to the propagation plane which are responsible for crack closure during loading. These stresses are much larger and spread over a wider area near the surface than in the center where they are almost negligible. Likewise, the values of the displacements perpendicular to the crack front (Figure 13b) are almost zero over a wider surface area near the edge, while, on the other hand, this area almost disappears at the center.
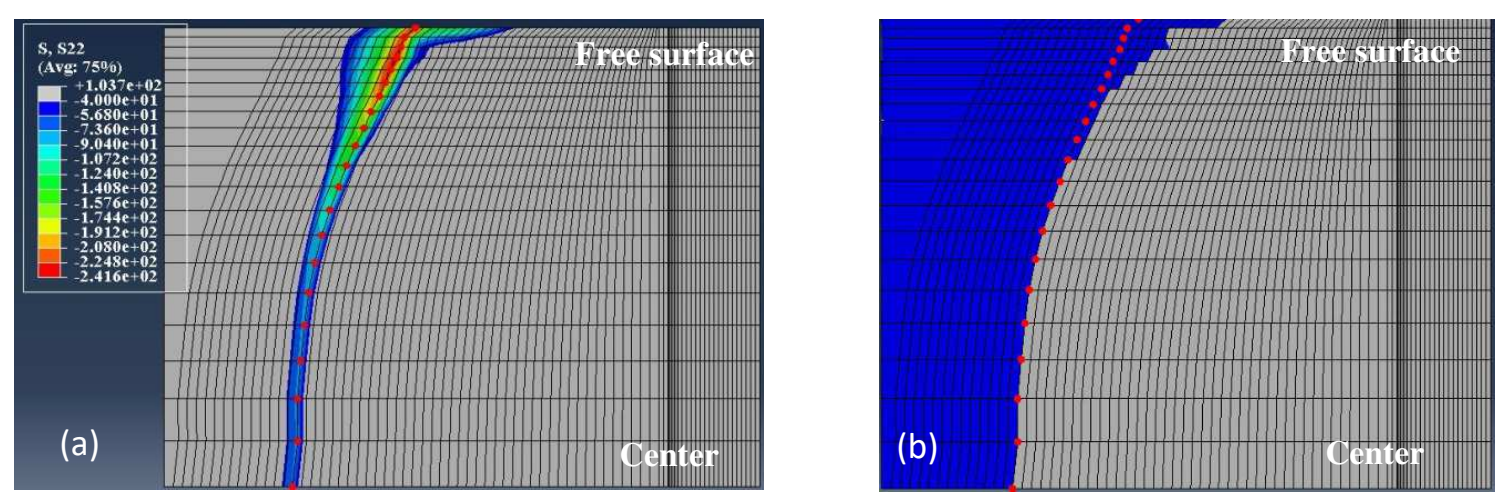

Figure 13: For $\Delta K=12 \mathrm{MPaVm} ; R=0.1$, free edge at $12.5 \%$ of maximum load (a) compressive $\sigma_{y y}$ stresses surrounding the crack front and perpendicular to the propagation plane (b) Displacements perpendicular to the crack front $U_{y}$; (light gray: $U_{y}>$ 0 , dark blue: $\left.U_{y}<0\right)$ 

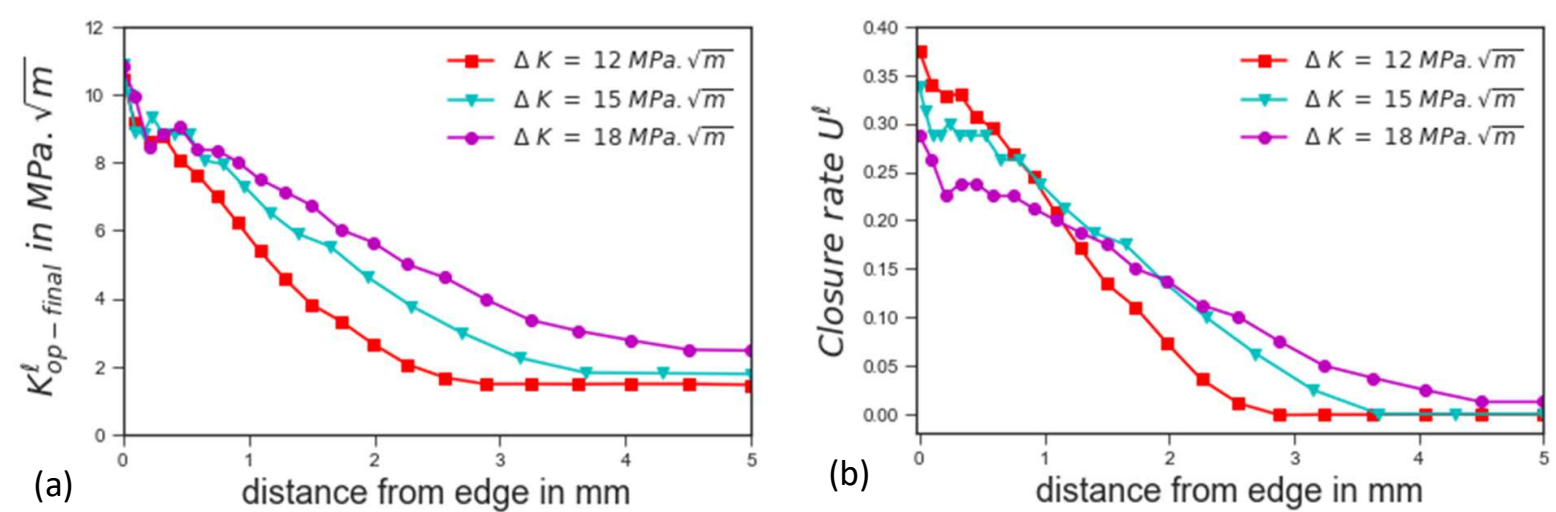

Figure 14: Evolution along the thickness of (a) the local opening stress intensity factor for the final front (b) the associated crack closure rate; 'spline' crack front, different loadings with $R=0.1$

The same general behavior is observed for the two other loading conditions $\Delta \mathrm{K}=15$ and 18 $\mathrm{MPa} \sqrt{\mathrm{m}}, \mathrm{R}=0.1$ (Figure 14a). However, two main observations emerge with the increase in the applied load. The first lies in the portion of the thickness influenced by crack closure. As shown in Figure $14 \mathrm{~b}$, for $\Delta \mathrm{K}=12 \mathrm{MPa} \sqrt{\mathrm{m}}, 6$ nodes at the center are not in the closed zone, for $\Delta \mathrm{K}=15$ $\mathrm{MPa} \sqrt{\mathrm{m}}$ they are only 3 , while for $\Delta \mathrm{K}=18 \mathrm{MPa} \sqrt{\mathrm{m}}$ all the nodes, even those of the center, are subjected to closure. The other observation lies in the closure rate values: near the free surface, as the applied load increases, the crack closure rate values slightly decrease. In that zone, the maximum closure rates are worth respectively $0.38,0.35$ and 0.3 for $\Delta \mathrm{K}=12,15$, and $18 \mathrm{MPa} \sqrt{\mathrm{m}}$. This decrease has also been observed in the 2D study done by Lin et al [50] on 316L where the digital image correlation was used to measure the local displacement ahead of the crack tip: the closure was more pronounced in $\Delta \mathrm{K}=15 \mathrm{MPa} \sqrt{\mathrm{m}}, \mathrm{R}=0.1$ than in $\Delta \mathrm{K}=20 \mathrm{MPa} \sqrt{\mathrm{m}}, \mathrm{R}=0.1$ which is in turn greater than in $\Delta \mathrm{K}=25 \mathrm{MPa} \sqrt{\mathrm{m}}, \mathrm{R}=0.1$. Furthermore, during his study, Vor [36] monitored that crack closure measured, globally, in specimens subjected to constant cyclic loading, is the same for different values of applied $\Delta K$ with the same loading ratio and tested that for $\Delta K=12$, 15 , and $18 \mathrm{MPa} \sqrt{\mathrm{m}}$ at $\mathrm{R}=0.1$. The results obtained here can explain these observations as it can be 
noticed that the areas below the crack closure rate curves in Figure 14b, calculated using a trapezoidal integral approximation, are very close for the different loading conditions. This means that the global amount of crack closure induced in the neighborhood of the crack front is the same for the different loading conditions at the same loading ratio; however, the distribution of this crack closure along the thickness is different depending the value of $\Delta \mathrm{K}$.

\subsubsection{Evolution of the local effective stress intensity factor range $\Delta \mathrm{K}_{\mathrm{eff}}^{\ell}$}

The values of the local effective stress intensity factor range $\Delta K_{e f f}^{\ell}=K_{\max }^{\ell}-K_{o p}^{\ell}$ along the thickness, for the final stabilized fronts are presented in Figure 15, for the different applied $\Delta \mathrm{K}$ values. The figure shows clearly that the values of $\Delta K_{\text {eff }}^{\ell}$ all along the thickness tend to converge towards a single constant value when stabilized. It appears that, as expected, as the load increases, the stabilized local values increase.

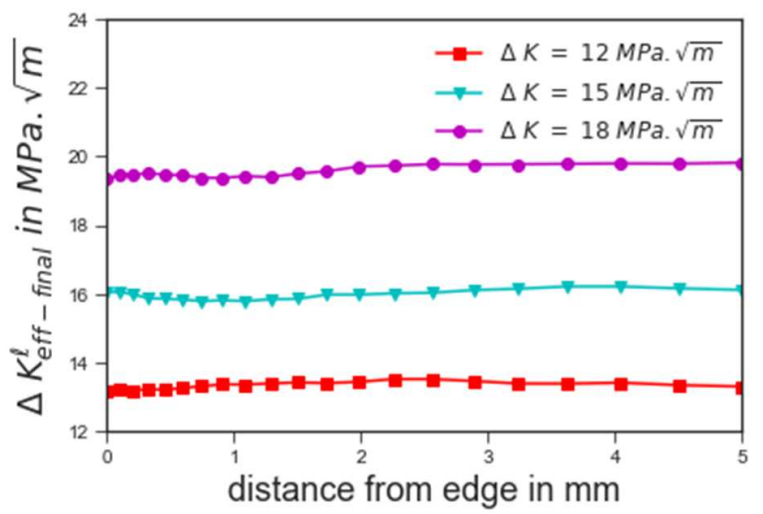

Figure 15: Stabilized curves of $\Delta K_{e f f}^{\ell} v$ v distance from edge for different applied loading conditions at $R=0.1$

The final crack fronts are then compared to elliptical interpolations in Figure 16. As the value of the applied load $\Delta \mathrm{K}$ increases, a slight difference between the final 'spline' crack front and its elliptical interpolation is observed. For $\Delta \mathrm{K}=12 \mathrm{MPa} \sqrt{\mathrm{m}}$, the final curve almost coincides with its elliptical interpolation, while for the other conditions there exists a small difference. This may also 
explain why Gardin et al [38] used a predefined shape with a $4^{\text {th }}$ degree polynomial for these conditions instead of an ellipse for $\Delta \mathrm{K}=12 \mathrm{MPa} \sqrt{\mathrm{m}}$.
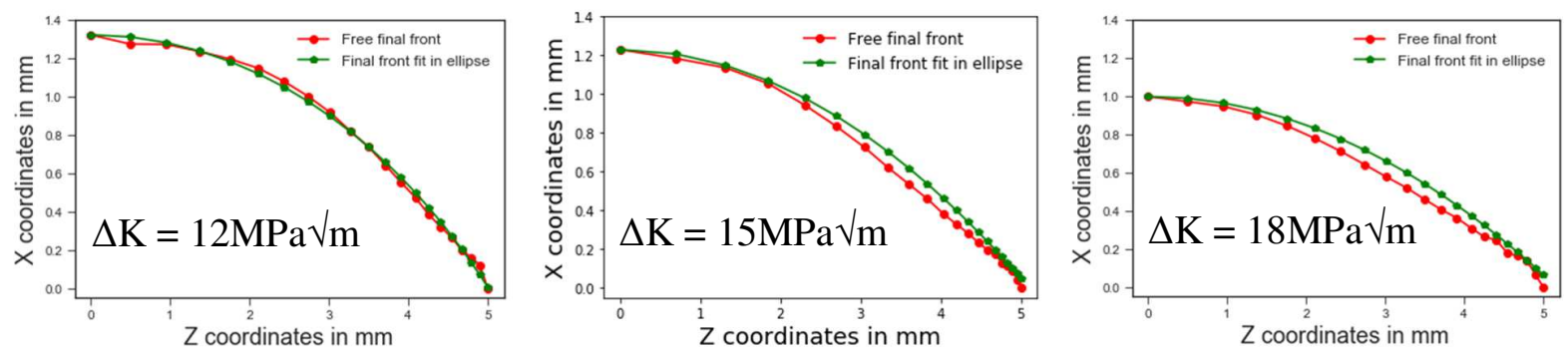

Figure 16: comparison of the final front shapes with their elliptical interpolation at $R=0.1$ for:

\section{Comparison between experiments and numerical predictions}

The preceding numerical results are now compared with previously obtained experimental results [36], [38], [40].

\subsection{Absence of crack closure}

Figure 17a compares the numerical crack front obtained with the experimental one for $\Delta \mathrm{K}=$ $4 \mathrm{MPa} \sqrt{ } \mathrm{m}, \mathrm{R}=0.7$. The numerical crack front is very close. There is a small difference that could probably be related to the fact that this loading condition is close to the propagation threshold and then can be influenced by the environment and the microstructure. In this case, due to the extremely long duration of the constant loading test at $4 \mathrm{MPa} \sqrt{\mathrm{m}}$, the comparison is only based on a single experimental front. For $\Delta \mathrm{K}=12 \mathrm{MPa} \sqrt{\mathrm{m}}, \mathrm{R}=0.7$ (Figure $17 \mathrm{~b}$ ), the difference between the numerical and the experimental fronts is important for the three stabilized experimental crack fronts. 

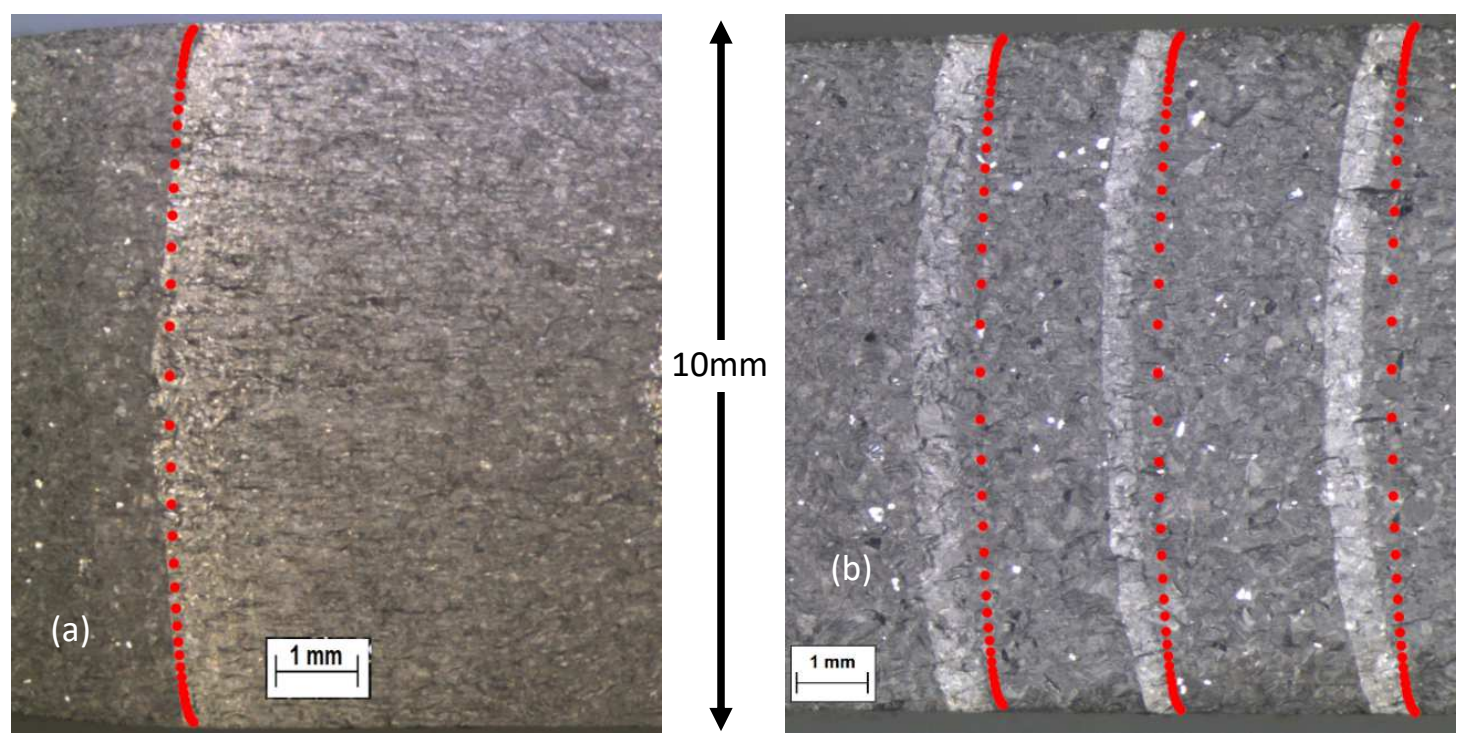

Figure 17: Comparison between the numerical and experimental results using the stress method [38] (a) $\Delta K=4 M P a V m ; R=$

0.7 (b) $\Delta K=12 \mathrm{MPaVm} ; R=0.7$

\subsection{Presence of crack closure}

For the cases with a noticeable crack closure, the comparison between the numerical and experimental final fronts for $\Delta \mathrm{K}=12,15$ and $18 \mathrm{MPa} \sqrt{\mathrm{m}}$ at $\mathrm{R}=0.1$ is presented respectively in Figure $18 \mathrm{a}, \mathrm{b}$ and c. For $\Delta \mathrm{K}=12 \mathrm{MPa} \sqrt{\mathrm{m}}$, the predicted fronts match very well with the experimental ones. For $\Delta \mathrm{K}=15 \mathrm{MPa} \sqrt{\mathrm{m}}$, the numerical fronts seem to be a little further from the experimental one, in particular near the free surface. For $\Delta \mathrm{K}=18 \mathrm{MPa} \sqrt{\mathrm{m}}$, the difference between predictions and experiments is even larger.

It can be noticed that, when the level of loading increases, the divergence between the numerical and experimental curves increases. 
(a)
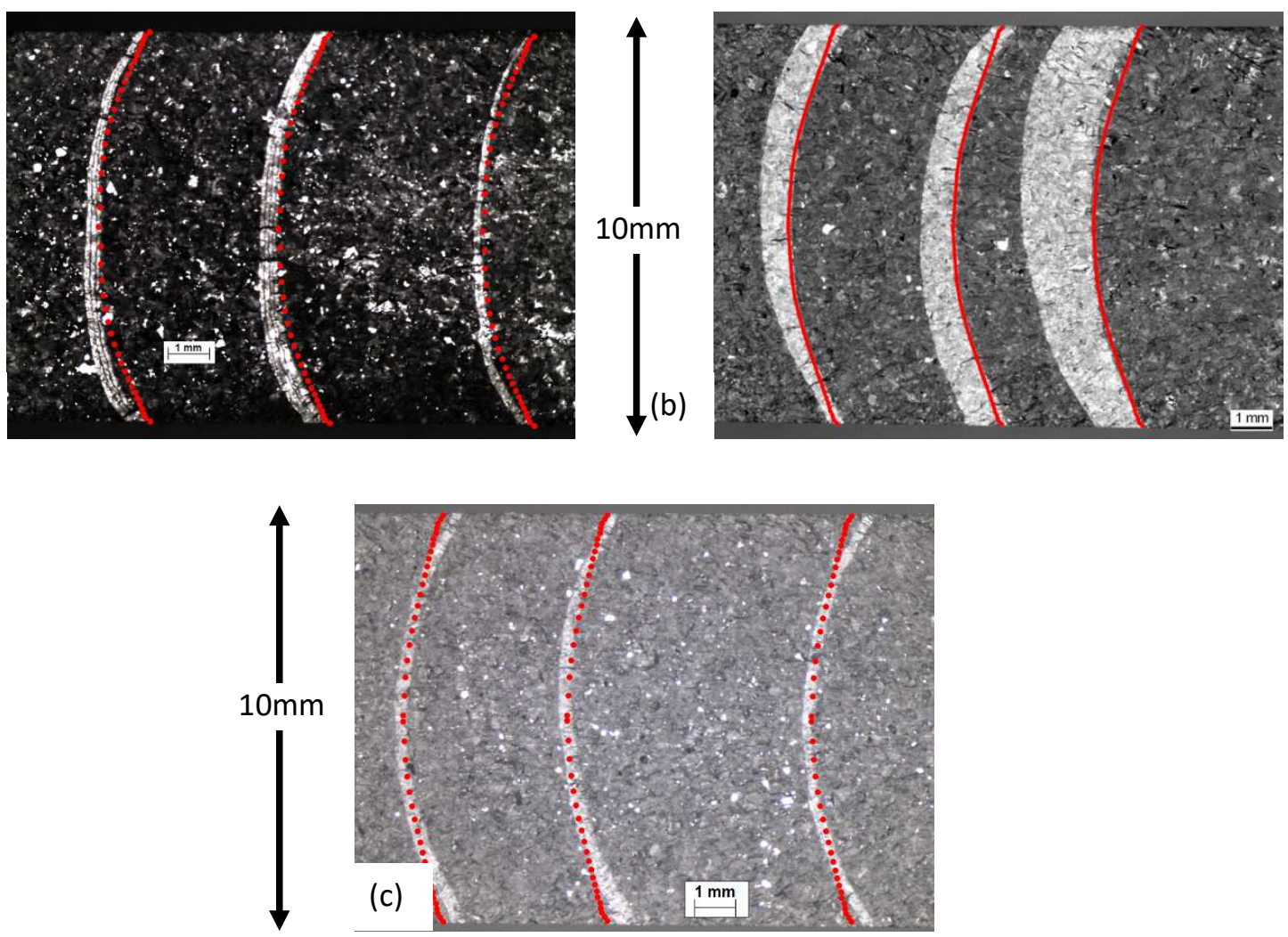

Figure 18: Comparison between the numerical and experimental results for (a) $\Delta K=12 \mathrm{MPaVm} ; R=0.1$ (b) $\Delta K=15 \mathrm{MPaVm}$; $R=0.1$ (a) $\Delta K=18 \mathrm{MPaVm} ; R=0.1$

\section{Discussion:}

In this section, the comparison between the obtained numerical results and the experimental ones is discussed in order to evaluate the accuracy of the model and the methodology developed. In this aim, the crack curvature is quantified through the parameter $\Delta \mathrm{a}_{\mathrm{f}-\mathrm{c}}$, corresponding to the difference between the crack length at the center and that at the free surface. The obtained values are summarized in Table 3 for the different loading conditions and according to the different approaches used. 
For $\Delta \mathrm{K}=4 \mathrm{MPa} \sqrt{\mathrm{m}}, \mathrm{R}=0.7$, simulated in elasticity, $\Delta \mathrm{a}_{\mathrm{f}-\mathrm{c}}$ is equal to $0.35 \mathrm{~mm}$. This value deviates by about $12 \%$ from the experimental value of $0.4 \mathrm{~mm}$. The simulation is also done using an elastoplastic behavior law to demonstrate the absence of crack closure. The result (not presented here) is close to that obtained with the elastic behavior with a small improvement: the predicted $\Delta \mathrm{a}_{\mathrm{f}-\mathrm{c}}$ becomes equal to $0.38 \mathrm{~mm}$ with only $5 \%$ deviation from experiments.

For $\Delta \mathrm{K}=12 \mathrm{MPa} \sqrt{\mathrm{m}}, \mathrm{R}=0.7$, the numerical $\Delta \mathrm{a}_{\mathrm{f}-\mathrm{c}}$ is the same as that calculated for $\Delta \mathrm{K}=4 \mathrm{MPa} \sqrt{\mathrm{m}}$, $\mathrm{R}=0.7$, because of the elastic behavior considered. Therefore, the difference between the experimental front $\left(\Delta \mathrm{a}_{\mathrm{f}-\mathrm{c}}=0.68 \mathrm{~mm}\right)$ and the predicted one is really important and close to $50 \%$. Almost the same result was found using the elastoplastic behavior law. On the other hand, the numerical results obtained by Fiordalisi [38] show that the final crack front calculated by Shih and Asaro is not very far from that calculated with the stress field method with $\Delta \mathrm{af}_{\mathrm{f} c \mathrm{c}}$ equals to $0.32 \mathrm{~mm}$. This large difference between the numerical and experimental results may be related to the fact that, in this case, the high loading conditions create a high amount of plasticity and thus an environment of generalized plasticity

Table 3 : Comparison of crack curvature between numerical and experimental results for different loading conditions

\begin{tabular}{|c|c|c|c|c|}
\hline & \\
\hline & & $\mathrm{K}_{\max }(\mathrm{MPa} \sqrt{\mathrm{m}})$ & $\Delta \mathrm{a}_{\mathrm{f}-\mathrm{c}}(\mathrm{mm})$ & Error $(\%)$ \\
\hline \multirow{4}{*}{$\begin{array}{c}\Delta \mathrm{K}=4 \mathrm{MPa} \sqrt{\mathrm{m}} \\
\mathrm{R}=0.7 \\
(\text { No closure })\end{array}$} & Experimental & \multirow{4}{*}{13.33} & 0.40 & \\
\hline & Stress fields' method (elastic) & & 0.35 & 12 \\
\hline & Stress fields' method (elasto plastic) & & 0.38 & 5 \\
\hline & $\begin{array}{c}\text { Shih \& Asaro method } \\
\text { (Fiordalisi } \Delta \mathrm{K}=12 \mathrm{MPa} \sqrt{\mathrm{m} \mathrm{R}}=0.7 \text { ) }\end{array}$ & & 0.32 & 20 \\
\hline \multirow{3}{*}{$\begin{array}{c}\Delta \mathrm{K}=12 \mathrm{MPa} \sqrt{\mathrm{m}} \\
\mathrm{R}=0.1\end{array}$} & Experimental & \multirow{3}{*}{13.33} & $1.21 \pm 0.08$ & \\
\hline & Stress fields' method & & 1.28 & 5 \\
\hline & Shih \& Asaro method (Fiordalisi [38]) & & 1.34 & 11 \\
\hline \multirow{2}{*}{$\begin{array}{c}\Delta \mathrm{K}=15 \mathrm{MPa} \sqrt{\mathrm{m}} \\
\mathrm{R}=0.1\end{array}$} & Experimental & \multirow{2}{*}{16.66} & $1.38 \pm 0.1$ & \\
\hline & Stress fields' method & & 1.23 & 12 \\
\hline
\end{tabular}




\begin{tabular}{|c|c|c|c|c|}
\hline & Shih \& Asaro method (Fiordalisi [38]) & & 1.26 & 8 \\
\hline \multirow{3}{*}{$\begin{array}{c}\Delta \mathrm{K}=18 \mathrm{MPa} \sqrt{\mathrm{m}} \\
\mathrm{R}=0.1\end{array}$} & Experimental & \multirow{3}{*}{20} & $1.40 \pm 0.15$ & \\
\hline & Stress fields' method & & 1 & 28 \\
\hline & Shih \& Asaro method (Fiordalisi) & & 1.16 & 17 \\
\hline \multirow{3}{*}{$\begin{array}{c}\Delta \mathrm{K}=12 \mathrm{MPa} \sqrt{\mathrm{m}} \\
\mathrm{R}=0.7 \\
(\text { No closure })\end{array}$} & Experimental & \multirow{3}{*}{40} & $0.68 \pm 0.07$ & \\
\hline & Stress fields' method & & 0.38 & 44 \\
\hline & Shih \& Asaro method (Fiordalisi [38]) & & 0.32 & 53 \\
\hline
\end{tabular}

Moreover, as the maximum applied stress intensity factor increases, the error between the numerical and the experimental values increases. The smallest error is obtained for $\Delta \mathrm{K}=$ $12 \mathrm{MPa} \sqrt{\mathrm{m}}, \mathrm{R}=0.1$ and $\Delta \mathrm{K}=4 \mathrm{MPa} \sqrt{\mathrm{m}}, \mathrm{R}=0.7$ and corresponds to a divergence of approximately $5 \%$ from the experimental results. This error increases to about $15 \%$ for $\Delta \mathrm{K}=15 \mathrm{MPa} \sqrt{\mathrm{m}}, \mathrm{R}=0.1$ and to $30 \%$ for $\Delta \mathrm{K}=18 \mathrm{MPa} \sqrt{\mathrm{m}}, \mathrm{R}=0.1$, to reach its maximum of $50 \%$ at $\Delta \mathrm{K}=12 \mathrm{MPa} \sqrt{\mathrm{m}}, \mathrm{R}=$ 0.7 with the highest maximum load applied. These observations are also valid with the Shih and Asaro method, except for certain values which may change a little bit, depending on the predefined front shape imposed. Nevertheless, the results obtained show that, for all the conditions of loading, there exists a small difference between the two methods used.

Finally, the results presented above show that the procedure used to describe the propagation of cracks is only accurate for two loading conditions $\Delta \mathrm{K}=12 \mathrm{MPa} \sqrt{\mathrm{m}} ; \mathrm{R}=0.1$ and $\Delta \mathrm{K}=4 \mathrm{MPa} \sqrt{\mathrm{m}}$, $\mathrm{R}=0.7$. For all the other loading conditions, $\Delta \mathrm{K}=12 \mathrm{MPa} \sqrt{\mathrm{m}} ; \mathrm{R}=0.7, \Delta \mathrm{K}=15 \mathrm{MPa} \sqrt{\mathrm{m}} ; \mathrm{R}=0.1$ and $\Delta \mathrm{K}=18 \mathrm{MPa} \sqrt{\mathrm{m}} ; \mathrm{R}=0.1$, notable deviations exist. In addition, it can be noticed that the difference between the numerical and experimental results increases as the load increases. Thus, and knowing the influence of $K_{\max }^{\ell}$ on the size of the plastic zone in the vicinity of the crack tip, a directly proportional relation can be built between the increase in the size of the plastic zone and the increase in the divergence with the experimental results. 
In fact, the increase in the size of the plastic zone seems to affect the earlier assumptions concerning the use of linear elastic fracture mechanics for the calculation of $K_{\max }^{\ell}$. According to the norms, the plastic zone size must remain smaller than a quarter of the crack length to correspond to small scale yielding assumptions [51]. In its specifications, ASTM E647[44] provides recommendations to specify to what extent the linear elastic fracture mechanics remains applicable as presented in the following equation:

$$
W-a>\frac{4}{\pi}\left(\frac{K_{\max }}{\sigma_{y}}\right)^{2}
$$

Although this equation depends on the plastic zone predictions provided by Irwin and although a noticeable difference is present with three dimensional predictions of the plastic zone while studying plasticity above, the margin remains wide enough to clearly respect the limits. Table 4 presents a comparison between the main characteristic dimensions of the crack and the results of the ASTM E647 [44] standard.

Where ' $\mathrm{a}$ ' is the length of the crack and ' $\mathrm{W}$ ' is the length of the ligament of the specimen.

Table 4 : Validation of the applicability of small scale yielding depending on the loading conditions applied

\begin{tabular}{|c|c|c|c|c|}
\hline & $\operatorname{Min}(\mathbf{a}) \mathbf{m m}$ & $\operatorname{Min}(\mathbf{W}-\mathbf{a}) \mathbf{m m}$ & $\frac{4}{\pi}\left(\frac{K_{\max }}{\sigma_{y}}\right)^{2} \mathbf{m m}[44]$ & Small scale yielding \\
\hline$\Delta \mathrm{K}=4 \mathrm{MPa} \sqrt{\mathrm{m}}, \mathrm{R}=0.7$ & \multirow{5}{*}{25.1} & \multirow{5}{*}{20} & 16.53 & Yes \\
\hline$\Delta \mathrm{K}=12 \mathrm{MPa} \sqrt{\mathrm{m}}, \mathrm{R}=0.1$ & & & 16.53 & Yes \\
\hline$\Delta \mathrm{K}=15 \mathrm{MPa} \sqrt{\mathrm{m}}, \mathrm{R}=0.1$ & & & 25.84 & No \\
\hline$\Delta \mathrm{K}=18 \mathrm{MPa} \sqrt{\mathrm{m}}, \mathrm{R}=0.1$ & & & 37.217 & No \\
\hline$\Delta \mathrm{K}=12 \mathrm{MPa} \sqrt{\mathrm{m}}, \mathrm{R}=0.7$ & & & 148.8 & No \\
\hline
\end{tabular}


Table 4 clearly demonstrates that, only under the conditions $\Delta \mathrm{K}=12 \mathrm{MPa} \sqrt{\mathrm{m}}, \mathrm{R}=0.1$ and $\Delta \mathrm{K}=$ $4 \mathrm{MPa} \sqrt{ } \mathrm{m}, \mathrm{R}=0.7$, where the plastic zone size is smaller than the limits defined by ASTM, LEFM can be used. For the other loading conditions, with a size of the plastic zone approximately 4 times greater than ' $\mathrm{W}$-a' in the case $\Delta \mathrm{K}=12 \mathrm{MPa} \sqrt{ } \mathrm{m}, \mathrm{R}=0.7$, where the greatest error is recorded, LEFM cannot be used.

The same behavior was observed by Fiordalisi [38] when using the Shih and Asaro method integrated in ABAQUS and which also depends on the validity of the LEFM. The error is higher with the increase of the dimensions of the plastic zone except in some cases due to the difference in the shape used for the crack front. The stress fields' method, which doesn't impose any assumption on the stress state, unlike the Shih and Asaro method, appears to be the best for the calculation of $K_{\text {max }}^{\ell}$ in the loading conditions $\Delta \mathrm{K}=12 \mathrm{MPa} \sqrt{\mathrm{m}} ; \mathrm{R}=0.1$ and $\Delta \mathrm{K}=4 \mathrm{MPa} \sqrt{\mathrm{m}}, \mathrm{R}=$ 0.7 where LEFM is shown to be applicable.

\section{Conclusion and Perspectives}

This article presents a 3D numerical method for the prediction of the crack front shape during propagation. This method relies on the stress intensity factor calculated based on the stress fields developed in the vicinity of the crack, while taking into account the influence of the plasticity induced crack closure. The results obtained lead to the following conclusions:

- The stress fields' method, corrected with the influence of the plasticity induced crack closure, is an efficient method to simulate three dimensional crack propagation in the small scale yielding domain where LEFM is still applicable, without any prior assumption of the stress state throughout the thickness. 
-The limitations of the stress fields' method are related to the increase of the plasticity in the vicinity of the crack tip due to load increase. The increase of plasticity violates the hypothesis studied by Westergaard and Irwin in confined plasticity.

-When considering small scale yielding domain, the results of the stress fields' method are better compared to Shih and Asaro method due to the dependence of the latter on the stress state considered by Abaqus as plane strain for three dimensional structures.

-The plasticity levels developed by Irwin in bi-dimensional studies and used by ASTM to define linear elastic fracture mechanics limits are not valid in three dimensional studies and should be studied case by case.

-The crack closure existence is mainly concentrated in the free surface region. For severe loading conditions, a smaller amount of crack closure can also be observed in the center.

-The final three dimensional stabilized form of the crack front is close to an ellipse.

The upcoming work, aims at introducing other elasto plastic driving forces in order to be able to consider intermediate and large scale yielding. Other efforts are also planned to optimize the methodology used in order to reduce in turn the duration of the simulations without affecting the quality of the results.

\section{Declaration of Competing Interest}

The authors declare that they have no known competing financial interests or personal relationships that could have appeared to influence the work reported in this paper.

\section{Acknowledgements}


The author acknowledges the French Ministry of Higher Education and Scientific Research for their financial support. 


\section{References}

[1] G. Irwin, 'Analysis of stresses and strains near the end of a crack traversing a plate', J. Appl. Mech., vol. 24, pp. 361-364, 1957.

[2] H.M. Westergaard, 'Stresses At A Crack, Size Of The Crack, And The Bending Of Reinforced Concrete', J. Proc., vol. 30, no. 11, pp. 93-102, 1933, doi: 10.14359/8300.

[3] I. S. Raju and J. C. Newman, 'Stress-intensity factors for a wide range of semi-elliptical surface cracks in finite-thickness plates', Eng. Fract. Mech., vol. 11, no. 4, pp. 817-829, 1979, doi: 10.1016/0013-7944(79)90139-5.

[4] A.B. de Morais, 'Calculation of stress intensity factors by the force method', Eng. Fract. Mech., vol. 74, pp. 739-750, 2007.

[5] Y.-S. Shih and J.-J. Chen, 'Analysis of fatigue crack growth on a cracked shaft', Int. J. Fatigue, vol. 6, no. 19, pp. 477-485, 1997.

[6] M. Åman, K. Berntsson, and G. Marquis, 'An efficient stress intensity factor evaluation method for interacting arbitrary shaped 3D cracks', Theor. Appl. Fract. Mech., vol. 109, p. 102767, 2020, doi: 10.1016/j.tafmec.2020.102767.

[7] D. Salimi-Majd, F. Shahabi, and B. Mohammadi, 'Effective local stress intensity factor criterion for prediction of crack growth trajectory under mixed mode fracture conditions', Theor. Appl. Fract. Mech., vol. 85, pp. 207-216, 2016, doi: https://doi.org/10.1016/j.tafmec.2016.01.009.

[8] Y.-L. Lu, 'A practical procedure for evaluating SIFs along fronts of semi-elliptical surface cracks at weld toes in complex stress fields', Int. J. Fatigue, vol. 18, no. 2, pp. 127-135, 1996, doi: 10.1016/0142-1123(95)00012-7.

[9] R. Branco, F. V. Antunes, and R. F. Martins, 'Modelling fatigue crack propagation in CT specimens', Fatigue Fract. Eng. Mater. Struct., vol. 31, no. 6, pp. 452-465, 2008, doi: 10.1111/j.1460-2695.2008.01241.x.

[10] P. Yu and W. Guo, 'An equivalent thickness conception for prediction of surface fatigue crack growth life and shape evolution', Eng. Fract. Mech., vol. 93, pp. 65-74, 2012, doi: 10.1016/j.engfracmech.2012.06.008.

[11] C.-Y. Hou, 'Simultaneous simulation of closure behavior and shape development of fatigue surface cracks', Int. J. Fatigue, vol. 30, no. 6, pp. 1036-1046, 2008, doi: 10.1016/j.ijfatigue.2007.08.020.

[12] C.-Y. Hou, 'Simulation of surface crack shape evolution using the finite element technique and considering the crack closure effects', Int. J. Fatigue, vol. 33, no. 5, pp. 719-726, 2011, doi: 10.1016/j.ijfatigue.2010.11.022.

[13] S. Beretta, L. Patriarca, and S. Rabbolini, 'Stress Intensity Factor calculation from displacement fields', in Crack Tip Fields, 2017, vol. 11, no. 41, pp. 269-276.

[14] H. Cheng and X. Zhou, 'An energy-based criterion of crack branching and its application on the multidimensional space method', Int. J. Solids Struct., vol. 182, pp. 179-192, 2020. 
[15] P. A. Zugliani et al., 'Bonded composite repair of metallic pipeline using energy release rate method', J. Adhes. Sci. Technol., vol. 33, no. 19, pp. 2141-2156, 2019.

[16] A. A. Griffith, 'VI. The phenomena of rupture and flow in solids', Phil Trans R Soc Lond A, vol. 221, no. 582-593, pp. 163-198, 1921, doi: 10.1098/rsta.1921.0006.

[17] A.A. Griffith, 'The theory of rupture', First International Congress of Applied Mechanics, Delft, 1924.

[18] W. Elber, 'The Significance of Fatigue Crack Closure', Damage Toler. Aircr. Struct., vol. ASTM STP 486, pp. 230-242, 1971, doi: 10.1520/STP26680S.

[19] Jr J.C. Newman, 'Finite element analysis of fatigue crack propagation-including the effects of crack closure.', National Symposium on Fracture Mechanics, Rhode Island, 1974.

[20] J. C. Newman and J. J. Ruschau, 'The stress-level effect on fatigue-crack growth under constant-amplitude loading', Int. J. Fatigue, vol. 29, no. 9, pp. 1608-1615, 2007, doi: 10.1016/j.ijfatigue.2006.11.003.

[21] R. C. McClung, B. H. Thacker, and S. Roy, 'Finite element visualization of fatigue crack closure in plane stress and plane strain', Int. J. Fract., vol. 50, no. 1, pp. 27-49, 1991, doi: 10.1007/BF00035167.

[22] L.-W. Wei and M. N. James, 'A study of fatigue crack closure in polycarbonate CT specimens', Eng. Fract. Mech., vol. 66, no. 3, pp. 223-242, 2000, doi: 10.1016/S00137944(00)00014-X.

[23] J. C. Newman, 'A crack opening stress equation for fatigue crack growth', Int. J. Fract., vol. 24, no. 4, pp. R131-R135, 1984, doi: 10.1007/BF00020751.

[24] N. A. Fleck, 'Finite element analysis of plasticity-induced crack closure under plane strain conditions', Eng. Fract. Mech., vol. 25, no. 4, pp. 441-449, 1968, doi: 10.1016/00137944(86)90258-4.

[25] R. C. McClung, 'Crack Closure and Plastic Zone Sizes in Fatigue', Fatigue Fract. Eng. Mater. Struct., vol. 14, no. 4, pp. 455-468, 1991, doi: 10.1111/j.1460-2695.1991.tb00674.x.

[26] J. Liu, P. Du, X. Liu, and Q. Du, 'Modeling of fatigue crack growth closure considering the integrative effect of cyclic stress ratio, specimen thickness and Poisson's ratio', Chin. J. Mech. Eng., vol. 25, pp. 816-825, 2012, doi: 10.3901/CJME.2012.04.816.

[27] X. Huang, M. Torgeir, and W. Cui, 'An engineering model of fatigue crack growth under variable amplitude loading', Int. J. Fatigue, vol. 30, no. 1, pp. 2-10, 2008, doi: 10.1016/j.ijfatigue.2007.03.004.

[28] J. Codrington and A. Kotousov, 'A crack closure model of fatigue crack growth in plates of finite thickness under small-scale yielding conditions', Mech. Mater., vol. 41, no. 2, pp. 165-173, 2009, doi: 10.1016/j.mechmat.2008.10.002.

[29] H. D. Dill and C. R. Saff, 'Spectrum Crack Growth Prediction Method Based on Crack Surface Displacement and Contact Analyses', Fatigue Crack Growth Spectr. Loads, 1976, doi: 10.1520/STP33381S.

[30] H. Sehitoglu and W. Sun, 'Modeling of Plane Strain Fatigue Crack Closure', J. Eng. Mater. Technol., vol. 113, no. 1, pp. 31-40, 1991, doi: 10.1115/1.2903380. 
[31] W. Sun and H. Sehitoglu, 'Residual Stress Fields During Fatigue Crack Growth', Fatigue Fract. Eng. Mater. Struct., vol. 15, no. 2, pp. 115-128, 1992, doi: 10.1111/j.14602695.1992.tb00042.x.

[32] J. Wu and F. Ellyin, 'A study of fatigue crack closure by elastic-plastic finite element analysis for constant-amplitude loading', Int. J. Fract., vol. 82, no. 1, pp. 43-65, 1996, doi: 10.1007/BF00017863.

[33] H. Alizadeh, S. Simandjuntak, D. Smith, and M. Pavier, 'Prediction of fatigue crack growth rates using crack closure finite element analysis', Int. J. Fatigue, vol. 29, no. 9, pp. 17111715, 2007, doi: 10.1016/j.ijfatigue.2006.12.002.

[34] R. G. Chermahini, K. N. Shivakumar, J. C. Newman, and A. F. Blom, 'Three-Dimensional aspects of plasticity-induced fatigue crack closure', Eng. Fract. Mech., vol. 34, no. 2, pp. 393-401, 1989, doi: 10.1016/0013-7944(89)90152-5.

[35] D. Camas, J. Garcia-Manrique, F. V. Antunes, and A. Gonzalez-Herrera, 'Threedimensional fatigue crack closure numerical modelling: Crack growth scheme', Theor. Appl. Fract. Mech., vol. 108, p. 102623, Aug. 2020, doi: 10.1016/j.tafmec.2020.102623.

[36] K. Vor, C. Sarrazin-Baudoux, C. Gardin, and J. Petit, 'Wake history effect on closure of short and long fatigue crack in 304L stainless steel', Procedia Eng., vol. 2, no. 1, pp. 23272336, 2010, doi: 10.1016/j.proeng.2010.03.249.

[37] J. L. Chaboche, 'A review of some plasticity and viscoplasticity constitutive theories', Int. J. Plast., vol. 24, no. 10, pp. 1642-1693, 2008, doi: 10.1016/j.ijplas.2008.03.009.

[38] C. Gardin, S. Fiordalisi, C. Sarrazin-Baudoux, M. Gueguen, and J. Petit, 'Numerical prediction of crack front shape during fatigue propagation considering plasticity-induced crack closure', Int. J. Fatigue, vol. 88, pp. 68-77, 2016, doi: 10.1016/j.ijfatigue.2016.03.018.

[39] C. F. Shih and R. J. Asaro, 'Elastic-Plastic Analysis of Cracks on Bimaterial Interfaces: Part I-Small Scale Yielding', J. Appl. Mech., vol. 55, no. 2, pp. 299-316, 1988, doi: 10.1115/1.3173676.

[40] J. Petit and C. Sarrazin-Baudoux, 'Etude du seuil de propagation en fatigue des aciers inoxydables 304L et 316L'. LMPM, ISAE-ENSMA, 2001.

[41] S. Pommier, 'Cyclic plasticity and variable amplitude fatigue', Int. J. Fatigue, vol. 25, no. 9-11, pp. 983-997, 2003, doi: 10.1016/S0142-1123(03)00137-3.

[42] L. Taleb and G. Cailletaud, 'Cyclic accumulation of the inelastic strain in the 304L SS under stress control at room temperature: Ratcheting or creep?', Int. J. Plast., vol. 27, no. 12, pp. 1936-1958, 2011, doi: 10.1016/j.ijplas.2011.02.001.

[43] D. S. Dugdale, 'Yielding of steel sheets containing slits', J. Mech. Phys. Solids, vol. 8, no. 2, pp. 100-104, 1960, doi: 10.1016/0022-5096(60)90013-2.

[44] ASTM International, ASTM E647-05, Standard Test Method for Measurement of Fatigue Crack Growth Rates. West Conshohocken, PA, 2005.

[45] G.R. Irwin, 'Plastic zone near a crack and fracture toughness', Proc Seventh Sagamore Conf, vol. 5, pp. 63-78, 1960. 
[46] X. B. Lin and R. A. Smith, 'Finite element modelling of fatigue crack growth of surface cracked plates: Part I: The numerical technique', Eng. Fract. Mech., vol. 63, no. 5, pp. 503522, Jul. 1999, doi: 10.1016/S0013-7944(99)00040-5.

[47] X. B. Lin and R. A. Smith, 'Finite element modelling of fatigue crack growth of surface cracked plates: Part II: Crack shape change', Eng. Fract. Mech., vol. 63, no. 5, pp. 523-540, 1999, doi: 10.1016/S0013-7944(99)00041-7.

[48] X. B. Lin and R. A. Smith, 'Finite element modelling of fatigue crack growth of surface cracked plates: Part III: Stress intensity factor and fatigue crack growth life', Eng. Fract. Mech., vol. 63, no. 5, pp. 541-556, 1999, doi: 10.1016/S0013-7944(99)00042-9.

[49] T. Oplt, P. Hutar, P. Pokorný, L. Náhlík, Z. Chlup, and F. Berto, 'Effect of the free surface on the fatigue crack front curvature at high stress asymmetry', Int. J. Fatigue, vol. 118, pp. 249-261, Jan. 2019, doi: 10.1016/j.ijfatigue.2018.08.026.

[50] B. Lin, S. Alshammrei, T. Wigger, and J. Tong, 'Characterisation of fatigue crack tip field in the presence of significant plasticity', Theor. Appl. Fract. Mech., vol. 103, p. 102298, 2019, doi: https://doi.org/10.1016/j.tafmec.2019.102298.

[51] Norman E. Dowling, 'Fracture of Cracked Members', in Mechanical Behavior of Materials, Fourth Edition., 2013, pp. 334-416. 